\title{
El género Merremia (Convolvulaceae) en Venezuela
}

\author{
The genus Merremia (Convolvulaceae) in Venezuela
}

Hernán Ferrer-Pereira ${ }^{1 *}$, Yuribia Vivas-Arroyo ${ }^{1}$, Omaira Hokche $^{1}$, Shingo Nozawa ${ }^{1}$,
Silvia Pérez-Cortéz ${ }^{1}$, Leyda Rodríguez ${ }^{1}$, Julián Mostacero $^{1}$ \& Javier Estrada-Sánchez ${ }^{2 .}$

\begin{abstract}
Resumen
Se presenta el estudio taxonómico de Merremia (Convolvulaceae) en Venezuela utilizando el lenguaje DELTA, señalando nuevos aportes para el género. Se revisó material herborizado de herbarios venezolanos, confirmando la presencia de 12 especies de Merremia en Venezuela. Se elaboraron dos claves de determinación de especies, una considerando sólo caracteres vegetativos y otra con caracteres vegetativos y reproductivos. Se ofrecen descripciones detalladas de las especies. Se georreferenciaron los especímenes para determinar los mapas de distribución de especies, y se muestran nuevos reportes de distribución por estado.
\end{abstract}

Palabras clave: DELTA, flora, sistemática, taxonomía.

\begin{abstract}
A taxonomic study of Merremia (Convolvulaceae) from Venezuela was performed with the help of DELTA software, indicating new contributions for the genus. Dry samples from Venezuelan herbaria were reviewed, confirming the presence of 12 species of Merremia in Venezuela. Two identification keys were constructed, one considering only vegetative characters and the other grouping vegetative and reproductive characters. Detailed species descriptions are provided. Specimens were georeferenced to determine species distribution maps and new distribution reports for states are shown.
\end{abstract}

Key words: DELTA, flora, systematics, taxonomy.

\section{Introducción}

Merremia Dennst. ex Endl. fue empleado por vez primera por August Wilhelm Dennstedt en su revisión de los nombres "modernos" del Hortus Indicus Malabaricus de Hendrik van Rheede (Dennstedt 1818), donde designó como Merremia convolvulacea a una planta colectada por el propio Rheede y asignada con el nombre malabar de "Kudici-Valli", la cual se encuentra representada en la figura 27 del volumen 8 y acompañada por una descripción extensa del propio Rheede que aparece en la página 51(2). La validación del nombre fue realizada por Endlicher (1841) y por Hallier (1893), en una revisión para el género, donde enmendó la descripción y determinó la validez de Merremia como una entidad distinta a Ipomoea L., considerando la morfología del polen (Ooststroom \& van Hoogland 1953; Demissew 2001).
Actualmente, para diferenciar estos géneros se emplean, por una parte, las variaciones de forma y textura del cáliz, caracteres difíciles de evidenciar por lo que carecen de valor en las claves, y por otra, la preponderancia de especies con flores amarillas en Merremia, lo que es poco común en Ipomoea (Ferguson et al. 1977).

El género Merremia incluye entre 60 y 80 especies con distribución pantropical, mayormente representadas en Asia y África, y con cerca de 30 especies en el Nuevo Mundo. Para Venezuela, el número de taxones oscila entre 11 y 13 (Pittier et al. 1945; Austin 1982). La más reciente revisión del género (Tapias 2008) reporta la presencia de 12 especies de Merremia en Venezuela, tres de ellas restringidas a la región de Guayana, una especie endémica de los estados Lara y Yaracuy, y el resto con una amplia distribución en el país (Austin 1982; Austin \& Staples 1981, 1983).

\footnotetext{
'Gerencia de Investigación y Desarrollo, Fundación Instituto Botánico de Venezuela “Dr. Tobías Lasser”, Caracas, Venezuela, Apartado Postal 2156.

${ }^{2}$ Centro Jardín Botánico, Facultad Ciencias, Universidad de Los Andes, Apartado 52, La Hechicera, Mérida 5212, Venezuela.

*Autor para correspondencia: hferrerp@gmail.com
} 
Desde la publicación de Austin (1982) no se ha revisado el género Merremia. Las descripciones presentadas por Austin (1982) fueron extraídas de concepciones florísticas más amplias y no circunscritas a la variabilidad presente en los ejemplares venezolanos, y a su vez estas descripciones no son consistentes respecto a los caracteres considerados por el autor. De acuerdo a esto, considerando el incremento significativo de las colecciones en años recientes y, por lo tanto, del número de especímenes en los herbarios nacionales, se planteó el desarrollo de un estudio taxonómico del género Merremia para Venezuela, que incluye la nueva información disponible, así como el uso del paquete de programas DELTA.

\section{Materiales y Métodos}

El presente estudio se basó en material herborizado del género Merremia recolectado en Venezuela y depositado en los herbarios VEN, MY, PORT y GUYN, incluyendo los ejemplares tipo disponibles en físico en VEN y en las bases de datos en línea de los herbarios MO, NY y LINN, señalando la condición de referencia en el material seleccionado en las especies respectivas.

Para realizar el análisis morfológico, se procedió previamente a la recopilación de todas las descripciones y menciones de taxones del género para la flora venezolana, incluyendo los protólogos de todos aquellos taxones citados para el país. Así mismo, se listaron las diferentes determinaciones presentes en el material depositado en los herbarios con lo que se obtuvo una lista de taxones potenciales sobre los cuales se realizaron las observaciones y análisis para determinar posteriormente los taxones aceptados y su respectiva circunscripción morfológica. A partir de este listado, se indican los sinónimos taxonómicos por cada especie reportados a partir de material venezolano.

Para ello se elaboró una lista de caracteres/ estados usados en las descripciones y diagnosis de los taxones de este género; posteriormente, se realizaron observaciones de los ejemplares de herbario a fin de identificar la variación dentro de cada taxón potencial, para así ampliar y reconsiderar los caracteres y estados a ser usados en la codificación posterior. Para normalizar y estandarizar la terminología empleada en el análisis morfológico se utilizaron diferentes referencias bibliográficas: Hickey (1973, modificado por Dilcher 1974) para la morfología foliar, Weberling (1989) para la morfología de la inflorescencia, Bell (1991) para la descripción de las diferentes estructuras dentro de la inflorescencia; Payne (1978) y Nishida (1996) para describir los tricomas; los estudios de Hallier (1893, 1913), Ooststroom \& van Hoogland (1953) y Austin (1982) para la morfología floral quienes revisaron o describieron especies de este género. El resto de los órganos y caracteres, tales como cobertura de los tricomas, anisodinamia, morfología del fruto y de la semilla, forma y acrescencia de los sépalos durante la fructificación, se categorizaron a través de observaciones sobre los pliegos tratando de usar los términos más usuales ajustados a las definiciones de Font Quer (1953). Particularmente, para el carácter cobertura del indumento se definieron cualitativamente cuatro estados en función del porcentaje visible de epidermis en el órgano evaluado, tal como se reportó en Ferrer-Pereira et al. (2010). Con las observaciones realizadas sobre los pliegos, se construyó una matriz de caracteres-estados con el Editor Delta (Dallwitz \& Paine 1993). De cada taxón potencial se seleccionó un número de exsiccata (entre 1 y 17 pliegos) dependiendo de la disponibilidad de ejemplares y de la variabilidad detectada para cada uno de ellos, los cuales fueron descritos y sus valores de caracteres/estados fueron ingresados en la matriz del Editor Delta.

Para la caracterización del indumento en las especies venezolanas del género Merremia, se estableció un conjunto de estados a fin de hacer discretas las variables observadas. El indumento puede estar presente en estructuras vegetativas y reproductivas, las cuales se dividieron en formas planas y cilíndricas en vista de la variación de la cobertura, longitud y tipo de tricomas entre las mismas. Las formas planas en las estructuras vegetativas están representadas por las superficies de las hojas, mientras que las cilíndricas incluyen los pecíolos, peciolulos y tallos. En cuanto a las estructuras reproductivas, los pedúnculos y pedicelos se agruparon dentro de las formas cilíndricas, y las brácteas, bractéolas, sépalos y pétalos caracterizan las formas planas.

Una vez ingresados todos los datos descriptivos, se redujo la matriz suprimiendo aquellos caracteres monomórficos y los estados ausentes ya que no aportan información para la elaboración de descripciones y claves. También se determinó el número de caracteres que no expresan la representación completa de las fases fenológicas de cada taxón. 
Completado el proceso en Editor Delta, se ejecutaron las acciones del programa para obtener los siguientes productos: clave interactiva para cada uno de los taxones y los caracteres de la matriz (INTKEY); claves diagnósticas, y descripciones en lenguaje natural, con caracteres estandarizados y homogéneos entre los taxones estudiados.

La matriz de caracteres y estados del Editor DELTA y la clave interactiva de los taxones pueden ser solicitadas al autor por correo electrónico. Tanto las claves como las descripciones fueron editadas manualmente para corregir los errores semánticos y sintácticos derivados de las limitaciones de la aplicación INTKEY, la cual fue desarrollada para su uso en lengua inglesa.

Por otro lado, los datos obtenidos de los rótulos de los pliegos fueron ingresados en una base de datos en Microsoft Access, por medio de los cuales se obtuvo la lista de material citado, a través de la herramienta de combinación de correspondencia del Microsoft Word. Los pliegos ingresados en Access fueron georreferenciados para generar mapas de distribución de los taxones.

\section{Resultados y Discusión}

De acuerdo con la propuesta taxonómica de O'Donell (1941), las especies reportadas para Venezuela se han agrupado en sect. Cissoides (House) O'Donell, sect. Schizips (Griseb.) O'Donell y sect. Xanthips (Griseb.) Hall. f. Este arreglo seccional fue corroborado por Leite et al. (2005), analizando la morfología polínica de un grupo de especies de Brasil.

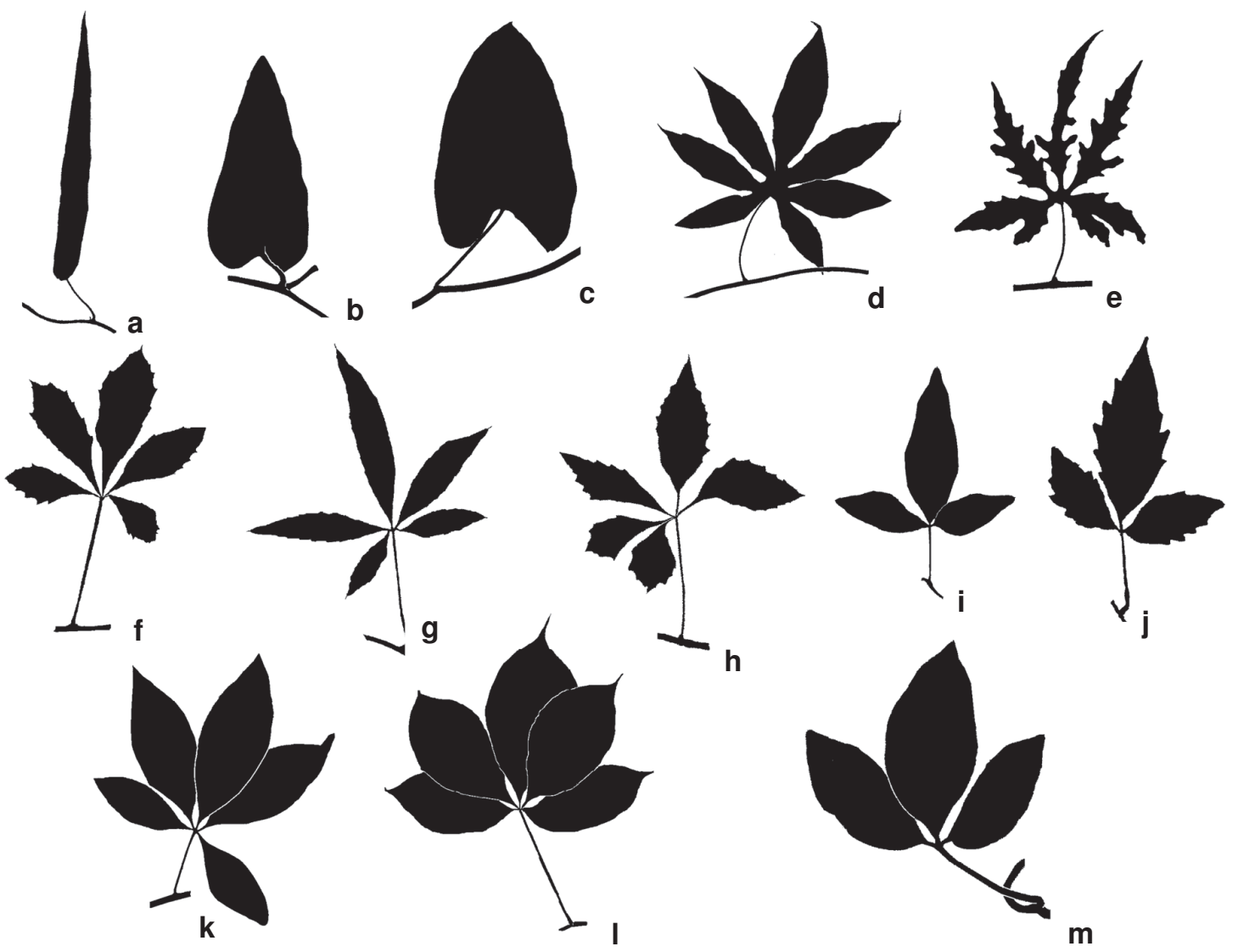

Figura 1 - Esquema de las láminas foliares de especies de Merremia en Venezuela: a. M. maypurensis; b. M. wurdackii; c. M. umbellata; d. M. tuberosa; e. M. dissecta; f. M. cissoides; g-h. M. quinquefolia; i-j. M. ternifoliola; k. M. macrocalyx; 1. M. aegyptia; m. M. nervosa.

Figure 1 - Leaf blades patterns of Merremia species from Venezuela: a. M. maypurensis; b. M. wurdackii; c. M. umbellata; d. M. tuberosa; e. M. dissecta; f. M. cissoides; g-h. M. quinquefolia; i-j. M. ternifoliola; k. M. macrocalyx; 1. M. aegyptia; m. M. nervosa. 


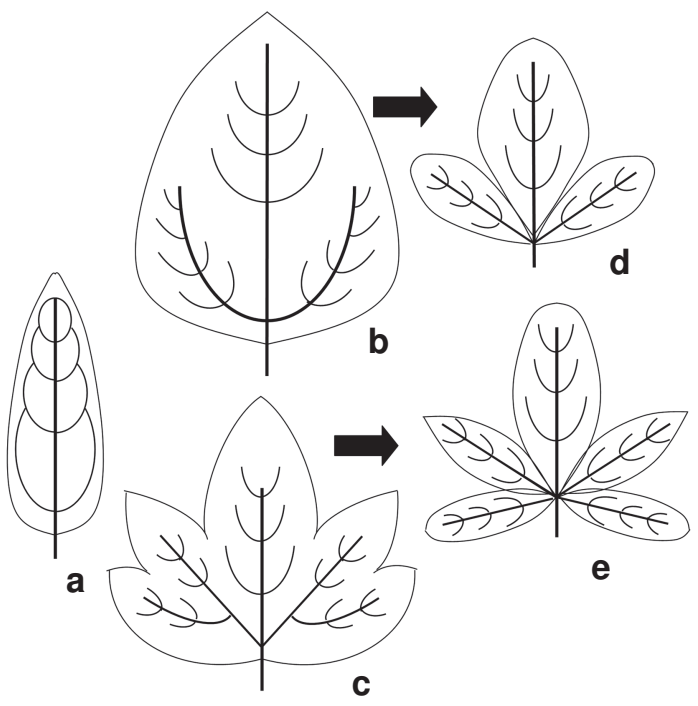

Figura 2 - Patrones de nerviación comúnmente observados en hojas de Merremia en Venezuela: a. broquidódroma; b. actinódroma; c. palinactinódroma; d-e. eucamptódroma en hojas compuestas. Las flechas indican una hipótesis de las vías de diversificación de la lámina foliar de acuerdo con el patrón de nerviación. Figure 2 - Venation patterns often observed in Merremia leaves: a. broquidodromous; b. actinodromous; c. palinactinodromous; d-e. eucamptodromous in compound leaves. Arrows show a hypothesis for laminae diversification according to the venation patterns.

\section{Morfología foliar}

Aunque en todas las especies de Merremia la lámina foliar, los folíolos y los sépalos siempre culminan en un mucrón, la diversidad morfológica de la hoja en otros caracteres es muy amplia (Fig. 1 y 2). Así, mientras que en todas las especies la hoja está bien desarrollada, en $M$. aturensis (Kunth) Hallier $\mathrm{f}$. se reduce a una estructura escuamiforme a deltoide adnata a los tallos. En el resto de las especies, las hojas son siempre pecioladas, pudiendo ser desde enteras hasta palmatisectas.

En las láminas enteras, los contornos van desde lanceolados (M. maypurensis Hall. f.) hasta cordados u orbiculares, como en M. umbellata (L.) Hallier f. y M. wurdackii D.F. Austin \& Staples; cuando lobuladas, pueden ser palmatífidas $[M$. tuberosa (L.) Rendle] o palmatisectas [M. dissecta (Jacq.) Hallier f.]. O bien, pueden ser perfectamente compuestas, presentándose como trifolioladas $(M$. nervosa Pittier y $M$. ternifoliola Pittier) o pentafolioladas [M. cissoides (Lam.) Hallier f., $M$. aegyptia (L.) Urb., M. quinquefolia (L.) Hallier f. y M. macrocalyx (Ruiz \& Pav.) O'Donell].
Aunque en lo referente al contorno de la lámina las especies son más o menos constantes, en caracteres como el margen del limbo foliar, los ápices y las bases se observa una gran variabilidad intraespecífica, siendo $M$. umbellata la especie más polimórfica en cuanto a la hoja se refiere. $\mathrm{La}$ variabilidad se presenta incluso intraindividuo, como en $M$. quinquefolia y $M$. ternifoliola, donde hay ejemplares con hojas disimiles, unas con el margen entero y otras aserradas.

Dada la presencia de las especies de Merremia en Venezuela, que representan casi la mitad de las propias del Neotrópico, se infieren al género todas estas variaciones en los patrones de nerviación observados en los taxones presentes en Venezuela. Así, tomando en cuenta que la derivación de láminas simples a láminas compuestas puede apreciarse como una homología dentro de las dicotiledóneas (Bharathan \& Sinha 2001; Champagne \& Sinha 2004) parece plausible considerar que el patrón actinódromo, compartido con las tribus basales de la familia Convolvulaceae (Stefanovic et al. 2002) es el estado más ancestral de la venación en Merremia, y que mediante cuatro eventos diferentes pudieron desarrollarse todos los patrones de venación actualmente observados.

El primer evento se relaciona con la disección de la lámina entera hasta alcanzar fragmentos en el nervio medio y en las dos venas laterales para dar origen a las hojas compuestas trifolioladas $(M$. nervosa, $M$. ternifoliola). Un segundo evento podría estar relacionado con la variación de la condición actinódroma a palinactinódroma que, conjuntamente con la disección de la lámina foliar, pudo originar las formas palmatífidas ( $M$. tuberosa, $M$. dissecta) y pentafolioladas (M. quinquefolia, $M$. cissoides, $M$. macrocalyx, M. aegyptia). El siguiente evento desencadenado condujo a la reducción del ancho de la lámina foliar y fusión de los lóbulos cordados de la base foliar, que por consecuencia indujeron a la variación de actinódroma a broquidódroma y la forma peltada en $M$. maypurensis, la cual pudo haber continuado hasta llegar a la reducción de la lámina observada en $M$. aturensis, o pudo ser independiente, por lo que se consideraría como un cuarto evento.

\section{Arquitectura de la inflorescencia y características de la flor}

El modelo tipológico de la inflorescencia de las especies estudiadas de Merremia sostiene la cima como unidad estructural. Se podría especular que, en la mayoría de las especies, el desarrollo de la 
inflorescencia involucra unidades monocasiales o dicasiales que luego se ramifican hasta formar inflorescencias compuestas o se reducen en inflorescencias unifloras (Fig. 3). En Merremia maypurensis, M. wurdackii y M. aturensis las inflorescencias quedan reducidas a una sola flor, muy raras veces se forman monocasios, mientras que en $M$. cissoides, $M$. dissecta, $M$. quinquefolia y M. ternifoliola hay una tendencia al desarrollo progresivo de las inflorescencias comenzando con una flor, a menudo dos o más en monocasios y drepanios cortos hasta llegar a drepanios compuestos en ocasiones excepcionales; incluso en $M$. dissecta, dos ejemplares presentaron dicasios compuestos. En $M$. macrocalyx, $M$. nervosa, $M$. tuberosa y $M$. aegyptia, existe una tendencia similar en las que se observan dicasios compuestos con mayor frecuencia. Merremia umbellata es el caso más interesante por presentar inflorescencias con apariencia umbeliforme que derivan de una aglomeración de drepanios donde el raquis se ha recortado.

En la mayoría de las especies de Merremia estudiadas se encontró variación morfológica entre los sépalos de una misma flor, siendo los dos más externos de mayor tamaño que los internos y con

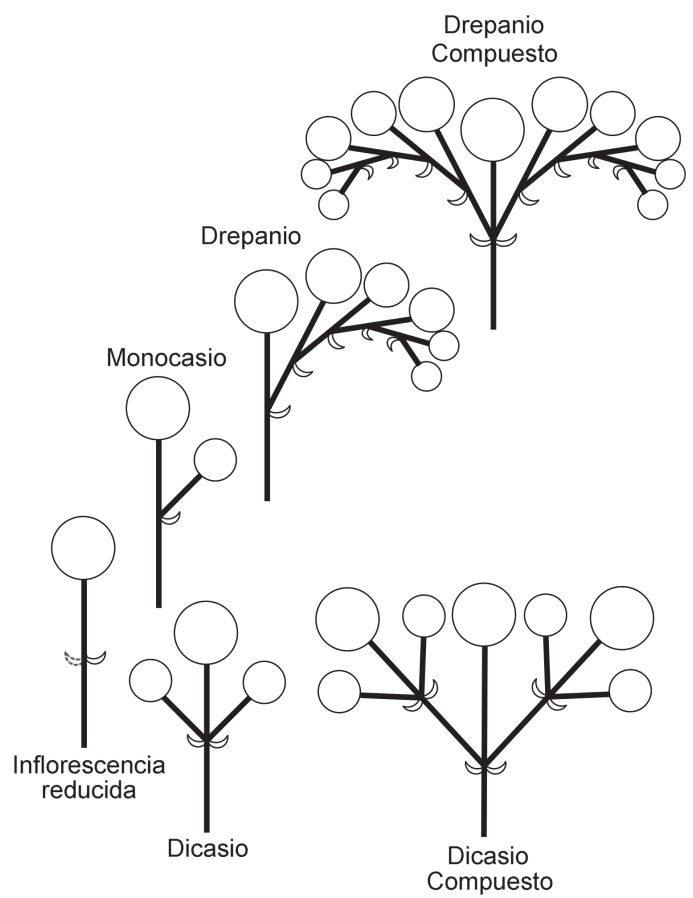

Figura 3 - Tipos de inflorescencias observadas en las especies de Merremia en Venezuela.

Figure 3 - Inflorescences types observed in Merremia species from Venezuela. frecuencia exhiben el indumento característico para cada especie.

Una de las características comúnmente utilizadas para identificar las especies de Merremia es el color de la corola, que con frecuencia suele ser blanca o amarilla, lo que concuerda con lo encontrado en este estudio, mientras que en Ipomoea, Jacquemontia Choisy y Operculina Silva Manso son generalmente moradas o azules. Otro carácter denotado por Hallier (1893) y Ooststroom \& van Hoogland (1953) son las bandas discoloras que se distinguen en el punto de fusión de los pétalos cuando las flores están secas. Para algunos taxónomos, este carácter sigue siendo útil para la identificación de secciones dentro del género. Esta característica se encontró en algunas especies de Merremia en Venezuela y se incluyó como carácter válido dentro de la descripción sin atribuirle valor taxonómico.

Austin (1982) señala que la antesis en Ipomoea comienza a partir de las primeras horas de la mañana, mientras que en Merremia ocurre en horas próximas al mediodía y se extiende hasta las primeras horas de la tarde, por lo que la diferencia temporal en el inicio de la antesis fue considerada por el autor como un carácter para separar ambos géneros. Es de hacer notar que durante las colecciones realizadas en campo, aún cuando no fue posible observar la antesis para todas las especies, se encontró que en $M$. dissecta, M. tuberosa, M. aegyptia y M. umbellata el inicio de la antesis coincide con las horas del mediodía, mientras que en $M$. ternifoliola, $M$. quinquefolia, $M$. cissoides y $M$. macrocalyx se observaron flores abiertas desde las primeras horas de la mañana y en raras ocasiones persisten hasta después del mediodía.

\section{Características del androceo}

O’Donell (1941) señaló que, en el género Merremia, los filamentos de los estambres tienen igual longitud o son poco desiguales. Esto difiere de lo encontrado en este trabajo donde se observaron dos tipos bien diferenciados por la longitud del filamento: didínamos (3 de mayor tamaño que los otros 2) en $M$. maypurensis, $M$. ternifoliola y $M$. umbellata, y anisodínamos (2 de mayor tamaño, 2 medianos y uno de más corto) en $M$. aegyptia, $M$. aturensis, $M$. nervosa, y $M$. tuberosa; en $M$. quinquefolia están presentes ambos estados. En el material revisado de $M$. cissoides, $M$. dissecta, $M$. macrocalyx y $M$. wurdackii fue difícil observar las características de los estambres puesto que las 
estructuras estaban deterioradas y/o la mayoría de las muestras estaban en fase de fructificación. Este carácter no ha sido indicado en la mayoría de las descripciones consultadas (Austin 1982; Ooststroom \& van Hoogland 1953).

La mayoría de las especies de Merremia presentes en Venezuela muestran una torción espiralada o helicoidal de las anteras, principalmente en la antesis, a diferencia de $M$. aturensis, $M$. tuberosa y $M$. umbellata que presentan las anteras rectas. Esto contradice lo expuesto por O’Donell (1941) para $M$. aturensis y $M$. tuberosa, y por Ooststroom \& van Hoogland (1953) para $M$. tuberosa, reportadas con anteras torcidas. SimãoBianchini \& Pirani (2005) reportaron que $M$. tuberosa y $M$. umbellata pueden tener dehiscencia completamente espiralada o sólo espiralada en el ápice de la antera. Sin embargo, este último estado no fue observado en las muestras examinadas en esta investigación, y se considera que debe ser evaluado con más profundidad utilizando ejemplares vivos y analizando el comportamiento de las anteras durante la antesis.

\section{Características de fruto y semilla}

Los frutos en Merremia son capsulares, globosos a globoso-ovados, dehiscentes en la mayoría de las especies, de 0,9-42 mm diám. La superficie del exocarpo generalmente es glabra y lisa, o rugosa como en $M$. maypurensis y $M$. wurdackii.

Los sépalos son persistentes en todas las especies estudiadas y acrescentes en todas, excepto en $M$. maypurensis y M. ternifoliola. Esto último no coincide con lo expuesto por Austin (1982), quien indicó la presencia de acrescencia para $M$. quinquefolia sobre especímenes venezolanos. Así mismo, contradice la falta de acrescencia indicada por este último en $M$. cissoides, pues todos los ejemplares observados en esta investigación presentan cálices acrescentes. Sin embargo, la presencia de la acrescencia observada en $M$. aegyptia, M. aturensis, M. dissecta, M. macrocalyx, M. tuberosa y $M$. umbellata coincide con lo señalado por O’Donell (1941), Ooststroom \& van Hoogland (1953), Austin (1982) y Rhui-cheng \& Staples (1995).

En casi todas las especies los sépalos son paralelos al eje cuando el fruto está en plena madurez, aunque ocasionalmente perpendiculares, es decir, patentes, como en $M$. cissoides, $M$. dissecta y $M$. macrocalyx. En esas especies, los sépalos son paralelos al eje en frutos inmaduros. Los sépalos acrescentes internos y externos son disimiles en cuanto a sus dimensiones, de tal modo que el más externo es de 39-52,7 × 24-43 mm, y el más interno de 35-56 × 25-40 mm, encontrándose los valores más altos en $M$. tuberosa y $M$. macrocalyx.

Los frutos presentan 1 a 4 septos, generalmente con 4 lóculos, menos comúnmente con 2 o 3 . El número de semillas oscila de 2 a 4 por fruto, siendo más frecuente 4, a excepción de $M$. maypurensis que presenta un solo lóculo con una sola semilla por fruto. En las exsiccata revisadas de $M$. aturensis, no se observaron muestras con fruto.

La forma de la semilla es trígona, en M. aegyptia puede ser trígona o bilobulada, mientras que en $M$. maypurensis y $M$. ternifoliola es ovoide, generalmente pubescente, aunque en $M$. macrocalyx, M. aegyptia, M. dissecta y $M$. wurdackii puede ser glabra. La longitud de la semilla oscila entre 3,5-27 mm, $M$. macrocalyx está en el extremo inferior del intervalo y $M$. tuberosa en el superior. No se observó material de semilla para $M$. aturensis en los pliegos revisados.

\section{Distribución y morfología de tricomas}

Se observaron tricomas filiformes, tuberculados, estrellados y glandulares, los cuales suelen ser translúcidos y amarillentos en la mayoría de las especies. En M. ternifoliola, M. umbellata y M. wurdackii pueden ser blancos y en $M$. cissoides se encontraron tricomas negruzcos. En $M$. cissoides y $M$. quinquefolia se pueden ver tricomas tuberculados y glandulares, tuberculados en $M$. aegyptia y estrellados en $M$. nervosa. La orientación es erecta en la mayoría de las especies; en $M$. ternifoliola, puede ser encrespada y en $M$. umbellata es adpresa o ascendente. La cobertura varía dentro de las especies entre laxa ( $M$. maypurensis), medianamente densa (M. cissoides) y densa (M. nervosa).

La mayoría de los especímenes evaluados de M. macrocalyx, M. maypuresis y $M$. tuberosa son glabros, mientras que en $M$. ternifoliola y $M$. umbellata pueden ser glabros o pubescentes.

Merremia Dennst. ex Endl., Gen. Pl. [Endlicher] Suppl. 1: 1403. 1841 (nom. cons.). Tipo: Merremia hederacea (Burm. f.) Hallier f.

Hierbas o arbustos, usualmente volubles, pero también hierbas postradas o erectas, o arbustos erectos de escasa estatura. Hojas generalmente pecioladas, de tamaño y forma variable, enteras, dentadas, lobuladas, palmatipartidas o compuestas (raramente muy pequeñas o subuladas) o bien 
palmadas con 3-5 folíolos, glabras o con pubescencia simple, glandular o estrellada. Flores axilares, solitarias o agrupadas en inflorescencias diversamente ramificadas (monocasios, drepanios simples y compuestos, dicasios simples y compuestos), axilares, pauci- a multifloras. Brácteas de la inflorescencia usualmente pequeñas, lineares a lanceoladas, de tamaño variable. Sépalos 5, usualmente subiguales, a veces los exteriores mayores o menores que los interiores, elípticos u ovados, obtusos, agudos o acuminados, mucronados, cóncavos, en varias especies acrescentes. Corola regular, infundibuliforme o campanulada, generalmente glabra, blanca, o amarilla, en algunos casos con 5 bandas distintivamente nervadas en el medio de los pétalos; limbo ligeramente 5-lobulado. Estambres 5, incluidos; anteras a menudo torcidas; filamentos filiformes, con frecuencia engrosados en la base, desiguales o apenas desiguales; polen liso, elipsoidal, 3-plegado o más raramente 6-plegado o dodecaédrico, pero siempre de más de 50 micrones diám. o con exina granulosa. Ovario casi siempre glabro, 2 a 4-loculado, 2-3 carpelar, a veces 4-locular por formación de falsos tabiques, pocas veces incompletamente 2loculado, 4 óvulos; estilo 1, simple, filiforme, incluido; estigma globoso o 2-globular. Disco a menudo anular. Fruto cápsular generalmente 4-loculada o más o menos irregularmente dehiscente, pericarpio apergaminado, delgado, 4-loculada, raras veces menos lóculos. Semillas 4 a 8, o menos por aborto, raramente 1, globosas o comprimidas lateralmente, glabras, pubescentes o villosas, especialmente en los márgenes; pelos simples, unicelulares o muy comúnmente de aspecto estrellado, multiramosos, en las que cada una de las ramas posee una célula basal y otra apical. Tricomas glandulares abundantes en los tallos y rodeando las nervaduras en las hojas, más raramente solitarias en la lámina.

\section{Clave para las especies de Merremia en Venezuela considerando sólo caracteres vegetativos}

1. Plantas frecuentemente erectas, hasta postradas, de tallos junciformes. Hojas reducidas, escuamiformes …...2. M. aturensis

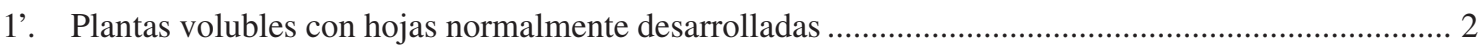

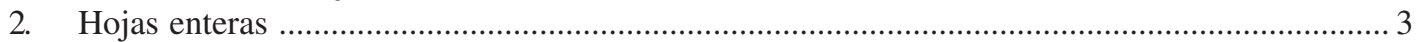

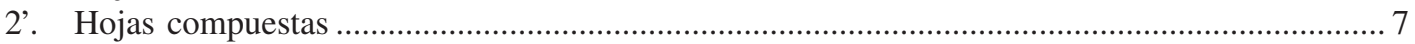

3. Hojas enteras de contorno lanceolado, ovado hasta orbicular, nunca lobuladas ................. 4

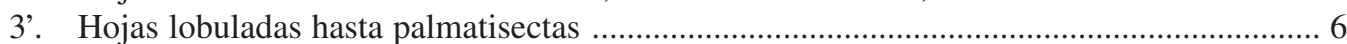

4. Hojas peltadas ..................................................................................... 6. M. maypurensis

4'. Hojas nunca peltadas, con base generalmente cordada ................................................ 5

5. Superficie de la cara abaxial irregular, de apariencia rugosa y poco diferenciable debido a la presencia de tricomas tuberculados, erectos .............. 12. M. wurdackii

5'. Superficie de la cara abaxial lisa, visible. Tricomas filiformes, cortos, erectos o adpresos, siempre presentes a lo largo de las venas incluso hasta del $5^{\circ}$ orden ......

11. M. umbellata

6. Hojas con borde eroso irregular; tallos y pecíolos con tricomas filiformes .....

4. M. dissecta

6'. Hojas con borde entero; tallos y pecíolos completamente glabros

10. M. tuberosa

7. Con 3 folíolos ............................................................................... 8

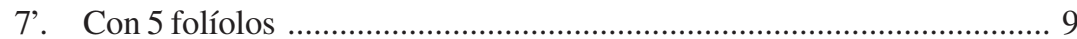

8. Tricomas estrellados cubriendo casi todas las estructuras ..............

7. M. nervosa

8'. Tricomas filiformes en tallos y pecíolos ............... 9. M. ternifoliola

9. Folíolos elípticos a lanceolados, siempre glabros, muy raras veces glabrescentes .................................. 5. M. macrocalyx

9'. Folíolos obovados a oblanceolados, con tricomas simples y/o glandulares ........................................................................ 10

10. Tallos y pecíolos con tricomas tuberculados, de color amarillo oscuro, con más 3,5 mm de longitud 
10'. Tallos y pecíolos con tricomas filiformes, blanquecinos, con longitud menor o igual a $3,5 \mathrm{~mm}$ 11

11. Tallos con tricomas filiformes y glandulares en toda su extensión 3. M. cissoides

11'. Tallos con tricomas filiformes, nunca glandulares, en su extensión 8. M. quinquefolia

\section{Clave para las especies de Merremia en Venezuela considerando caracteres vegetativos y reproductivos}

1. Hojas reducidas a escamas; plantas erectas, raramente postradas, glabras

2. M. aturensis

1'. Hojas desarrolladas; plantas postradas, volubles o lianas

2. Hojas enteras o lobuladas, pero no partidas hasta la base ....................................................... 3

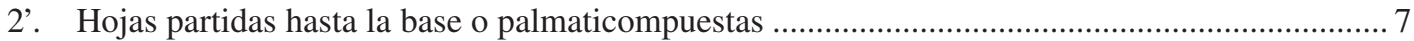

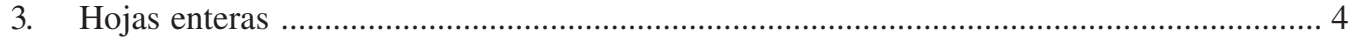

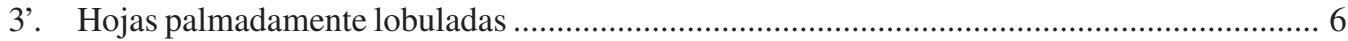

4'. Hojas 8-10 veces tan largas como anchas, linear-ovadas a linear-lanceoladas, peltadas cuando la base es redonda, pudiendo ser no peltadas cuando la base es cordada

6. M. maypurensis

4'. Hojas 2 a 4 veces tan largas como anchas, la base cordada a auriculada, nunca peltada ... 5

5. Inflorescencias umbeliformes con bractéolas caducas; corolas amarillas con pubescencia en los ápices de las bandas mesopetalinas. Especie de amplia distribución 11. M. umbellata

5'. Inflorescencias cimosas con pocas flores o flores solitarias con bractéolas persistentes; corolas amarillas completamente glabras. Especie de distribución restringida (Amazonas)

12. M. wurdackii

6. Tallos pubescentes con largos tricomas; lóbulos de la hoja obtusos; corola blanca con centro púrpura 4. M. dissecta

6. Tallos glabros; lóbulos de la hoja agudos; corola amarilla ..... 10. M. tuberosa

7. Hojas principalmente 3 -folioladas ........................................................... 8

7'. Hojas principalmente 5-folioladas .................................................... 9

8. Folíolos con indumento simple ............................ 9. M. ternifoliola

8'. Folíolos con indumento estrellado, densamente pubescentes en la cara abaxial 7. M. nervosa

9. Tallos y hojas generalmente glabros, raramente glabrescentes. Flores agrupadas en dicasios compuestos. Frutos con sépalos acrescentes y perpendiculares al eje floral .....5. M. macrocalyx

9'. Tallos y hojas generalmente cubiertos de tricomas simples (filiformes o tuberculados) y/o glandulares. Flores agrupadas en monocasios o drepanios. Frutos maduros con sépalos paralelos al eje 10

10. Tricomas glandulares ausentes, únicamente simples, alargados, de color amarillento. 1. M. aegyptia

10'. Tricomas glandulares acetabuliformes presentes ..... 11 11. Tricomas glandulares en todo el tallo 3. M. cissoides

11'. Tricomas glandulares sólo en el extremo apical del pedúnculo y/o los sépalos sépalos más externos 8. M. quinquefolia

1. Merremia aegyptia (L.) Urb., Symb. antill. 4:505. 1910. Ipomoea aegyptia L., Sp. pl. 162. 1753. Convolvulus pentaphyllus L., Sp. pl. 223. 1762, nom. superfl. illegit.

Figs. 4a, 5

Sufrútices o hierbas, volubles; tallos teretes, de 1,5-4,5 mm de diám., ligeramente costulados. Hojas compuestas, 5-folioladas; pecíolos teretes, de 33-100 $\times 0,5-2 \mathrm{~mm}$; peciólulos ausentes. Folíolos a menudo elípticos a ovados, rara vez obovados, concoloros, base aguda, ángulo basal agudo, margen entero, ápice acuminado, con mucrones; folíolo central 4,2-14,4× 1,6-5,9 cm; folíolos laterales 2,4-10,2×1,2-4,8 cm, 
nerviación broquidódroma. Tallos y pecíolos con tricomas, tuberculados, translúcidos o amarillentos, erectos, con cobertura por lo general medianamente densa o laxa, distribuidos en toda la extensión. Láminas foliares con tricomas en toda la superficie adaxial o en la zona entre nervaduras y en toda la cara abaxial, blancos, translúcidos o amarillentos; tuberculados, erectos, frecuentemente con cobertura laxa en ambas caras. Inflorescencias en dicasios compuestos, de 3-6 flores, a menudo con 2 grados de ramificación, que alcanzan 85-204mm de largo; pedúnculo terete, $50-139 \times 1-2,5 \mathrm{~mm}$, ocasionalmente ensanchado en la base; pedúnculos y pedicelos con tricomas en toda la superficie, translúcidos o amarillentos, tuberculados, erectos, con cobertura medianamente densa menos frecuentemente laxa; brácteas persistentes o caducas, ovadas; bractéolas ausentes. Flores de 3,05-3,6 cm de largo; pedicelos teretes o aplanados, 11-43 × 1-1,5 mm; cáliz de 5 sépalos, distinguidos en dos series, libres entre sí, prefloración imbricada, con tricomas en el tercio basal, en toda la superficie de la cara abaxial, translúcidos o amarillentos, tuberculados, generalmente erectos, con cobertura medianamente densa, rara vez densa, elípticos u ovados, obtusos en la base, margen entero por lo general sin consistencia membranácea, cóncavos, ápice obtuso a agudo, ocasionalmente con mucrones; sépalo más externo 16-19×6-11,5 mm, sépalo más interno 7-14 $\times 7-11 \mathrm{~mm}$, nervaduras conspicuas; corola de 5 pétalos, glabra, blanca; bandas mediapetalinas inconspicuas, ápice redondeado, sin mucrones; tubo de la corola $1,45-1,9 \times 0,7-0,95 \mathrm{~mm}$, nervaduras conspicuas; androceo de 5 estambres, adnatos a la corola, libres entre sí, inclusos, insertos en el tercio inferior de la corola, anisodínamos $(2+2+1)$, filamentos 3,5-7 mm; con tricomas, distribuidos en el tercio basal, anteras oblongas, de 2,5-3,5 × 1-1,2 mm, basifijas, con dehiscencia introrsa, frecuentemente torcidas en la antesis; gineceo sincárpico, de 2 carpelos, con 2 lóculos, disco anular, ovario globoso u ovado, glabro, estigmas 2 , esféricos, placentación axilar, con 2 óvulos por lóculo. Fruto dehiscente, globoso, de $12 \mathrm{~mm}$ de diám., superficie del exocarpo lisa, glabra; sépalos persistentes y acrescentes en el fruto; sépalo acrescente más externo 18-24×9-12,5 $\mathrm{mm}$, sépalo acrescente más interno 13-16×9-11 mm, paralelos al eje, con 4 septos, 4 lóculos. Semillas bilobuladas o lateralmente comprimidas, 4 por fruto, de 4-5,5 mm de largo, glabras.

Material seleccionado: ANZOÁTEGUI: Puerto La Cruz, 25.XII.1924, fl., H. Pittier 11643 (VEN). APURE: Payarita, entre San Fernando y Achaguas, Bajo Apure, 20.XI.1972, fl., M. Ramia \& R. Montes 4958 (VEN). ARAGUA: Distrito Mariño, Turmero, 3.X.1978, fl., V. Mateu 13 (VEN). BOLÍVAR: Municipio Autónomo Heres, Ciudad Bolívar, Jardín Botánico del Orinoco, 4.IV.1995, fl., Y. Salazar 16 (VEN). CARABOBO: alrededores de Valencia, 8.XII.1919, fl., H. Pittier 8671 (VEN). DISTRITO CAPITAL: Parroquia
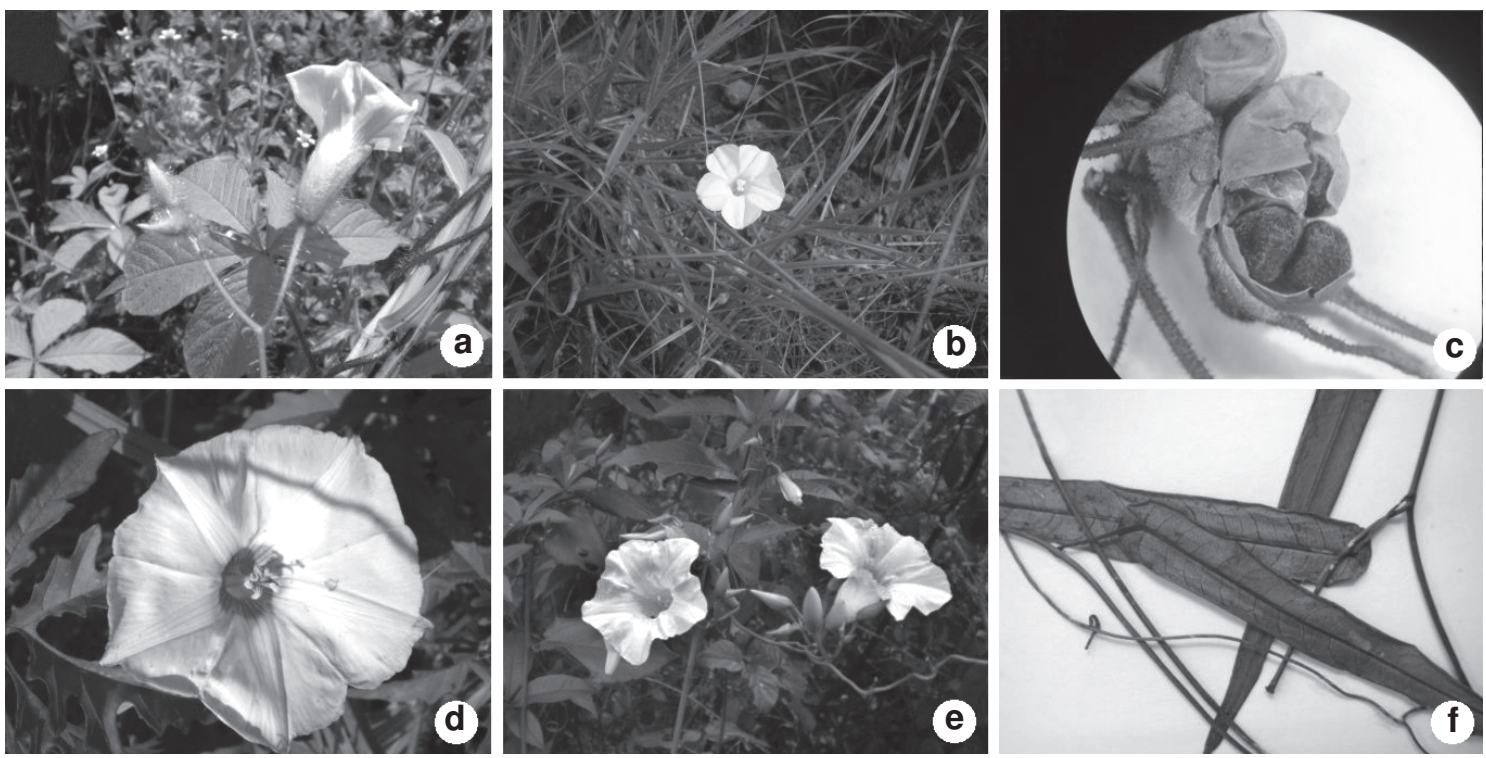

Figura 4 - Especies de Merremia en Venezuela: a. M. aegyptia; b. M. aturensis; c. M. cissoides; d. M. dissecta; e. M. macrocalyx; f. M. maypurensis.

Figure 4 - Merremia species from Venezuela: a. M. aegyptia; b. M. aturensis; c. M. cissoides; d. M. dissecta; d. M. macrocalyx; e. M. maypurensis. 


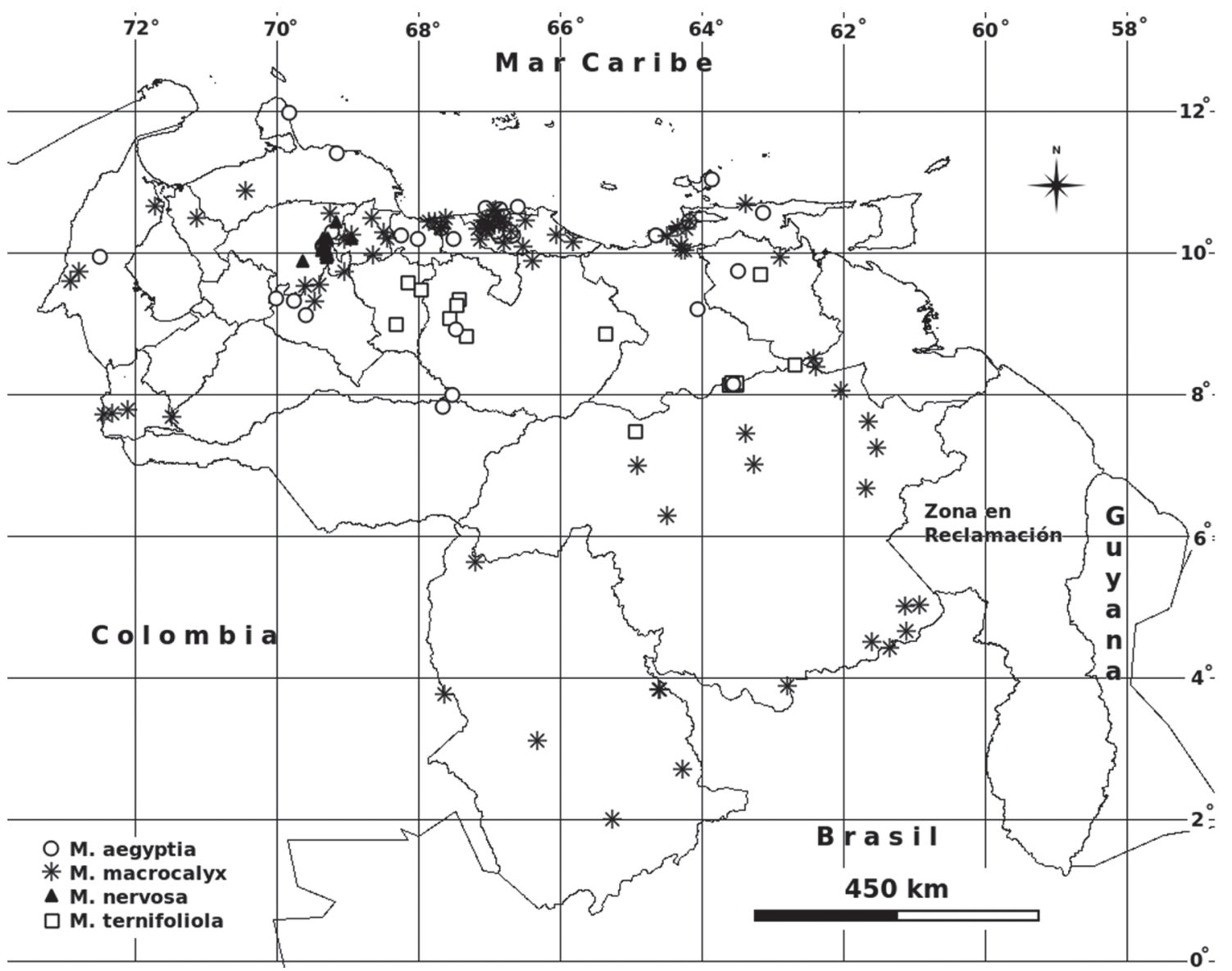

Figura 5- Mapa de distribución de Merremia aegyptia, M.macrocalyx, M.nervosa y M. ternifoliola en Venezuela. Figure 5 - Distribution map of Merrmia aegyptia, M.macrocalyx, M.nervosa and M. ternifoliola in Venezuela.

Santa Rosalia, Ciudad Universitaria, Colinas de Sierra Maestra, 13.XI.1979, fl., G. Rosales 15 (VEN). FALCÓN: carretera Píritu-Coro, 01-31.XII.1953, fl., T. Lasser \& L. Aristeguieta 3298 (VEN). GUÁRICO: 14 km N of San Fernando de Apure along main highway to Calabozo, 10.XI.1973, fr., $G$. Davidse et al. 3954 (VEN). LARA: Barquisimeto, 16.I.1969, fl., R. Smith V6074 (VEN). MIRANDA: Hacienda El Volcán, Santa Lucía, 16.XI.1918, fl., H. Pittier 8267 (VEN). MONAGAS: recently cleared area above floodplain of the Río Guarapiche ca. 2 km SSW of Jusepín, 20.II.1967, fl., $R$. Pursell et al. 8087(VEN). NUEVA ESPARTA: Atamo, Isla Margarita, 2.XI.1980, fl., J. Hoyos \& F. Delascio 4557(VEN). PORTUGUESA: selva a lo largo del Río María, Boca de Monte, $23 \mathrm{~km}$ al $\mathrm{N}$ del vado del Río Suruguapo, $38 \mathrm{~km}$ al N por la autopista Guanare-Ospino, en el sitio Las Marías, 3.XI.1982, fr., J. Steyermark et al. 127199 (VEN). SUCRE: Distrito Benítez, S of Guaraúnos, 18.II.1980, fl., J. Steyermark et al. 121251 (VEN). VARGAS: along Río Los Caracas above town of Los Caracas, 11.II.1973, fr., T. Croat 21585 (VEN). ZULIA: Distrito Perijá, carretera Maracaibo - La Fría (TÁCHIRA), en km 16 al S de Machiques, 14.XII.1977, fl., G. Bunting 5952 (VEN).
Colectada en casi todo el país (Fig. 5). Crece abundantemente en zonas de rastrojos y formaciones secundarias, desde el nivel del mar hasta $1.200 \mathrm{~m}$, en áreas abiertas de zonas urbanas y rurales. Se distingue principalmente por la presencia de tricomas tuberculados, conspicuos y largos, generalmente de color amarillento o pardo claro, que cubren casi todas las estructuras de la planta, excepto las flores, y por las inflorescencias dicasiales que agrupan hasta nueve flores blancas.

2. Merremia aturensis (Kunth) Hallier f., Bot. Jahrb. Syst. 16: 552. 1893. Convolvulus aturensis Kunth, Nov. Gen. sp. [H.B.K.] (quarto ed.) 3: 96. 1818.

Figs. $4 \mathrm{~b}, 6$

Ipomoea juncea Choisy in A.DC., Prodr. 9: 335. 1845.

Hierbas o sufrútices, generalmente erectas, raras veces postradas, tallos teretes o poligonales, 0,8-2,9 mm de diám., lisos. Hojas escuamiformes, 
enteras; pecíolos ausentes. Los rudimentos foliares deltoides, concoloros, glabros, con ángulo obtuso, margen entero, ápice agudo, sin mucrones, de 0,05$0,3 \times 0,02-0,66 \mathrm{~cm}$, nerviación inconspicua. Inflorescencias reducidas, muy raras veces con más de una flor formando monocasios o drepanios, 12 (44) $\mathrm{mm}$ de largo; pedúnculo terete o poligonal, 0,6-8,0 $\times$ $0,1-0,8 \mathrm{~mm}$, no ensanchado en la base; pedúnculos y pedicelos glabros; brácteas persistentes, ovadas, raras veces elípticas; bractéolas 2, persistentes, ovadas. Flores de 1,2-3,7 cm de largo; pedicelos poligonales o teretes, hasta $7 \times 1 \mathrm{~mm}$; cáliz de 4-5 sépalos, glabros, no distinguidos en dos series, libres entre sí, con prefloración imbricada, ovados, obtusos en la base, margen entero con consistencia membranácea, a menudo cóncavos o incluso rectos, ápice frecuentemente agudo a acuminado, con mucrones; sépalo más externo de 5-12 × 1,5-3 mm, sépalo más interno de 5-12×1,2-3,5 mm, nervaduras conspicuas o inconspicuas; corola de 5 pétalos, glabra, blanca, con margen entero o lobulado, bandas mediapetalinas concoloras; lóbulos con margen entero, ápice redondeado a atenuado, sin mucrones, de 1-3 $\times 8 \mathrm{~mm}$; tubo de la corola hasta $2,1 \times 1 \mathrm{~cm}$; limbo hasta $25 \mathrm{~mm}$ de diám., nervaduras conspicuas; androceo de 5 estambres, adnatos a la corola, libres entre sí, inclusos, insertos en el tercio inferior de la corola, anisodínamos $(2+2+1)$, filamentos 8-15 mm de largo, glabros o con tricomas distribuidos en toda la extensión o sólo en el tercio basal, anteras oblongas, 2-6 × 0,8-1 mm, basifijas, no torcidas en la antesis; gineceo sincárpico, de 4 carpelos, con 4 lóculos, disco anular, ovario ovado, glabro, estigmas $1 \mathrm{o} 2$, esféricos, con 1 óvulo por lóculo. Fruto no visto.

Material seleccionado: AMAZONAS: Departamento Atures, sabanas de la llanura del bajo y medio Río Parucito (Cuenca del Río Manapiare), 1.III.1979, fl., O. Huber 3550 (VEN). ANZOÁTEGUI: 17.VIII.1982, fl., $R$. Montes 1286 (MO). BOLÍVAR: Municipio Gran Sabana, Fundo Santa Teresa, al N de Santa Elena de Uairén, Laguna Encantada, 29.I.2007, fl., W. Díaz et al. 8671 (VEN).

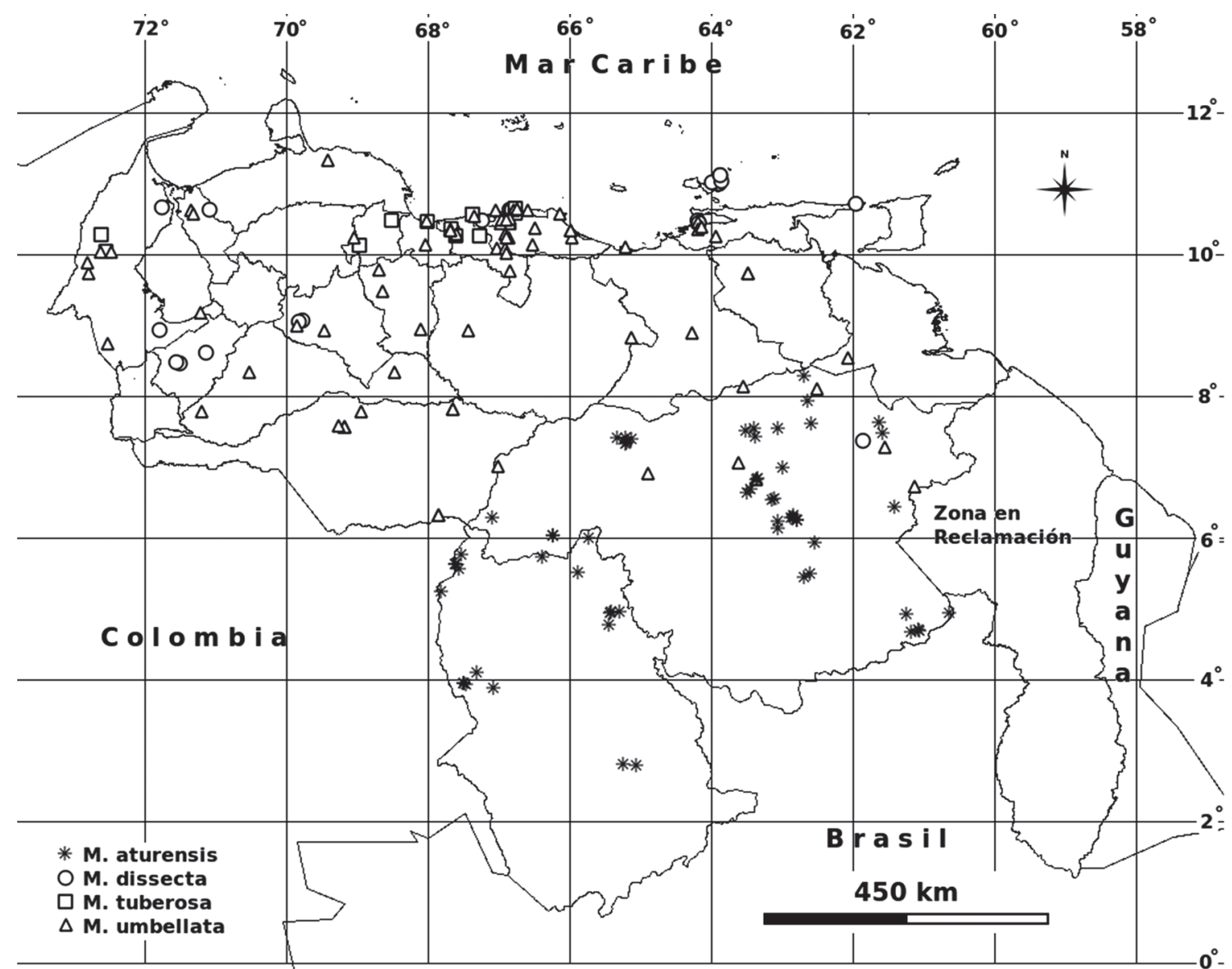

Figura 6 - Mapa de distribución de Merremia aturensis, M. dissecta, M. tuberosa y M. umbellata en Venezuela. Figure 6- Distribution map of Merremia aturensis, M. dissecta, M. tuberosa and M. umbellata in Venezuela. 
Única especie del género presente en Venezuela con ramas delgadas, áfilas y de porte suberecto a postrado. Crece al sur del Orinoco, entre 75 y $900 \mathrm{~m}$, pero se han encontrado poblaciones al norte del país en el estado Anzoátegui.

3. Merremia cissoides (Lam.) Hallier f., Bot. Jahrb. Syst. 16: 552. 1893. Convolvulus cissoides Lam., Tabl. encycl. 1:462.1793 ('1791'). Figs. 4c, 7

Convolvulus riparius Kunth, Nov. Gen. sp. [HBK] (quarto ed.) 3: 109. 1819 ('1818').

Convolvulus oronocensis Willd. ex Roem. \& Schult., Syst. veg. (ed. 15 bis) 4: 303. 1819.

Merremia parviflora Pittier, Bol. Soc. Venez.

Ci. Nat. 8: 143. 1943. Syn. nov.

Hierbas generalmente volubles, raras veces postradas; tallos teretes o poligonales, $1,2-1,8 \mathrm{~mm}$ de diám.; generalmente ligeramente costulados, raramente lisos. Hojas compuestas 5-folioladas, con folíolos sésiles, elípticos u ovados, discoloros o concoloros, nerviación craspedódroma simple, base atenuada, ángulo basal agudo, margen aserrado, ápice obtuso o acuminado, con mucrones; folíolo central 4,71-8,8 $\times$ 1,9-4cm; folíolos laterales $2,62-6,1 \times 1,28-3,6 \mathrm{~cm}$. Tallos y pecíolos con tricomas filiformes o glandulares, raramente con ambos tipos, translúcidos, amarillentos o negruzcos, erectos, con cobertura medianamente densa, distribuidos en toda la extensión. Láminas foliares con tricomas en toda la superficie, translúcidos o amarillentos, filiformes o glandulares, erectos, con cobertura medianamente densa en la cara adaxial, laxa o medianamente densa en la abaxial. Inflorescencias mayormente reducidas, en drepanios o en monocasios, hasta 4 flores, en 2 grados de ramificación, 33,5-45 mm; pedúnculo terete, $19-25 \times 0,3-0,8 \mathrm{~mm}$, no ensanchado en la base; pedúnculos y pedicelos con tricomas, en toda la superficie, translúcidos o amarillentos, filiformes, erectos, con cobertura medianamente densa o densa; brácteas ausentes; bractéolas 2, persistentes, lineares. Flores hasta 1,5 cm de largo; pedicelos teretes, 1,6-4x

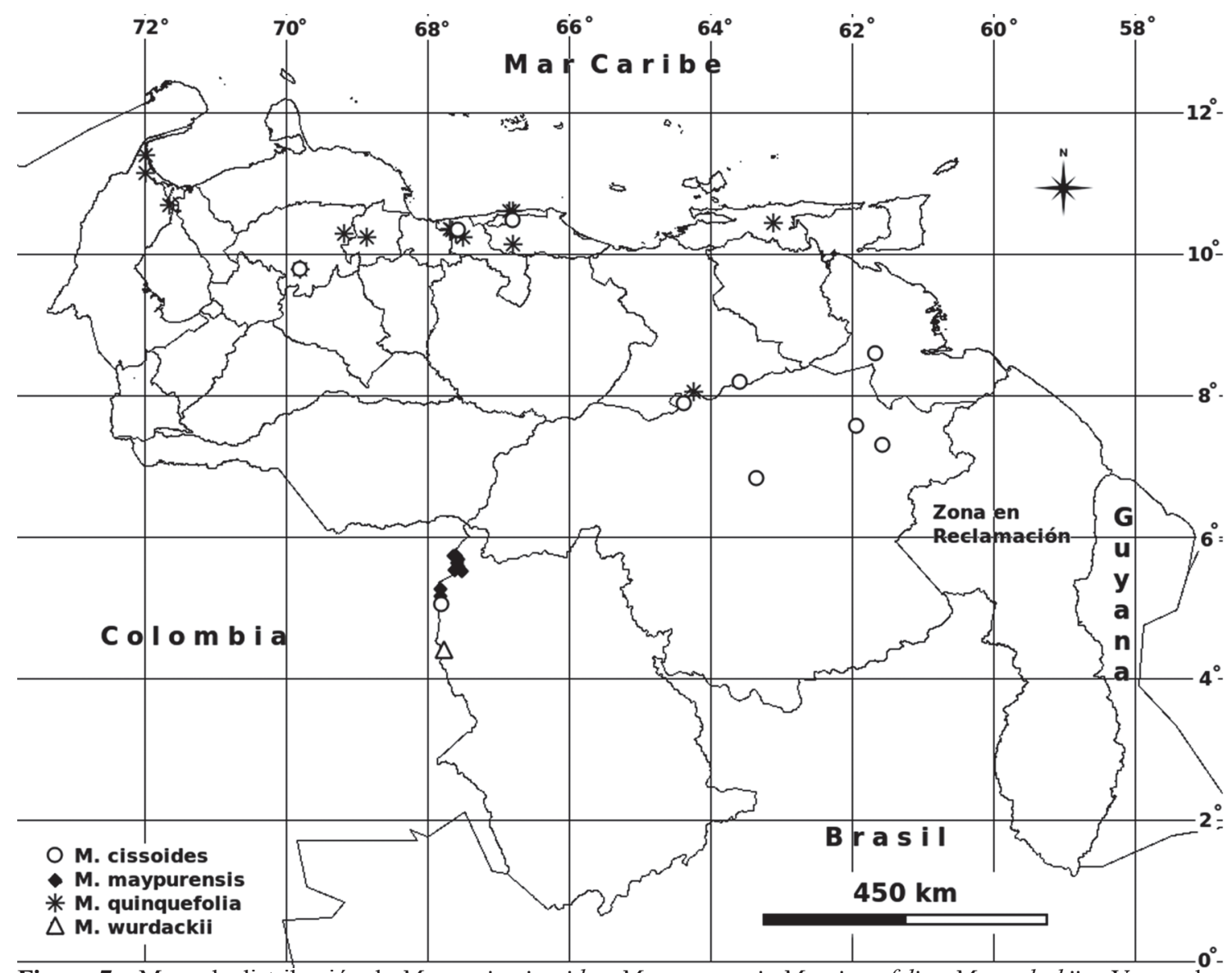

Figura 7 - Mapa de distribución de Merremia cissoides, M. maypurensis, M. quinquefolia y M. wurdackii en Venezuela. Figure 7 - Distribution map of Merremia cissoides, M. maypurensis, M. quinquefolia and M. wurdackii in Venezuela. 
0,6 mm; cáliz de 5 sépalos, muy raras veces 4, ovados, distinguidos o no en dos series, libres entre sí, prefloración imbricada, con tricomas en toda la superficie de la cara adaxial y abaxial, translúcidos o amarillentos, filiformes, erectos, con cobertura medianamente densa a densa; obtusos en la base, margen entero o aserrado con o sin consistencia membranácea, cóncavos, ápice agudo, acuminado o atenuado, generalmente con mucrones; sépalos entre 12-17,5 ×3,5 mm, nervaduras conspicuas o raramente inconspicuas; corola de 5 pétalos, blanca; androceo de 5 estambres, adnatos a la corola, libres entre sí, inclusos, anteras torcidas en la antesis; gineceo sincárpico, 4 carpelos, 4 lóculos, estigma 1, 1 óvulo por lóculo. Fruto dehiscente, deprimido globoso, 9,5 mm de diám., superficie del exocarpo lisa, glabra; sépalos persistentes y acrescentes en el fruto; sépalo acrescente más externo de $15,7 \times 6 \mathrm{~mm}$, perpendiculares al eje, con 2 septos, dehiscencia septicida, 4 lóculos. Semillas trígonas, 4 por fruto, de $3,9 \mathrm{~mm}$, con tricomas. Material seleccionado: AMAZONAS: Departamento Atures, alrededores de El Carmen, al extremo S de Isla Ratón, 15.II.1985, st., F. Guánchez \& G. Carnevali 3722 (VEN). ANZOÁTEGUI: Soledad, 21.XI1929, st., N. G. S. 152 (VEN). ARAGUA: aledañas a selvas en Urb. El Castaño, alrededores de Maracay, 19.II.1950, fr., M. Ponce \& B. Trujillo 1770 (MY). BOLÍVAR: Municipio Sifontes, Campus de FLASA, Tumeremo, 31.VIII.2000, fl., C. KnabVispo 1384 (VEN); sabana de La Paragua, 19.III.1940, fl., Ll. Williams 12670 (VEN, tipo de M. parviflora). DELTA AMACURO: alrededores de Sacupana, 1-31.XII.1959, fr., L. Aristeguieta 4023 (VEN). MIRANDA: cerros inmediatos a Petare, carretera a Santa Lucia, fr., B. Trujillo 4337 (MY).

Distribuida con mayor frecuencia en los estados Amazonas y Bolívar, raramente hacia el norte (Fig. 7), en zonas húmedas como orillas de bosques, desde los 35 hasta $300 \mathrm{~m}$. Puede confundirse con $M$. quinquefolia por su apariencia; sin embargo, puede diferenciarse por la presencia de tricomas glandulares sobre los tallos y pecíolos que nunca alcanzan los pedúnculos y sépalos de la flor, así como por la condición aguda de los sépalos la cual se acentúa durante la fructificación. Austin (1982) sinonimizó M. parviflora con $M$. quinquefolia; sin embargo, los resultados obtenidos en esta investigación permiten adjudicar a $M$. parviflora como nuevo sinónimo taxonómico de $M$. cissoides por la presencia de tricomas glandulares en las partes vegetativas.

4. Merremia dissecta (Jacq.) Hallier f., Bot. Jahrb. Syst. 16: 552. 1893. Convolvulus dissectus Observ. bot. 2: 4, pl. 28. 1767 .

Figs. 4d, 6

Hierbas volubles; tallos mayormente poligonales o menos frecuentemente teretes, de 1-2,6 mm diám, papilosos o ligeramente costulados. Hojas simples comúnmente palmatipartidas, raramente palmatilobuladas; pecíolos poligonales o aplanados, 40-85 × 0,6-1 mm; láminas ovadas u obovadas, generalmente 5-lobuladas pero los dos laterales basales dividido en dos, dando la apariencia de 7lobulada, discoloras o concoloras, 4,5-10 ×6,5-11,8 $\mathrm{cm}$, ángulo basal obtuso, margen aserrado y eroso, ápice agudo, con mucrones, nerviación mayormente actinódroma o raramente palinactinódroma. Tallos y pecíolos con tricomas filiformes, translúcidos o amarillentos. 2,5-4 mm de largo, erectos, con cobertura laxa o medianamente densa, distribuidos en toda la extensión o en el tercio basal o en el tercio apical. Láminas foliares glabras. Inflorescencias reducidas o en dicasios, 1-3 flores, que alcanzan 55-152 mm de largo.; pedúnculo terete, no ensanchado en la base, 25-90 × 0,6-1,5 mm; pedúnculos y pedicelos con tricomas, generalmente en la zona basal, algunas veces en la zona media o distal o raramente en toda la superficie, translúcidos y amarillentos o raramente ferrugíneos, filiformes, erectos, con cobertura laxa a medianamente densa; brácteas mayormente ausentes; bractéolas persistentes o caducas, solitarias cuando presentes. Flores de 3,25-4,5 cm de largo; pedicelos mayormente aplanados, teretes o poligonales, 15-30 $\times$ 0,5-1,2 mm; cáliz de 5 sépalos, distinguidos en dos series, libres entre sí, glabros, elípticos u ovados, obtusos en la base, margen entero con o sin consistencia membranácea, rectos o cóncavos, ápice obtuso o agudo, con mucrones; sépalo más externo 17-22 ×6,5-10 mm, sépalo más interno 23 mm de largo, nervaduras conspicuas o inconspicuas; corola de 5 pétalos, glabra, con margen entero, prefloración valvada-induplicada, blanca o blanco-cremosa con garganta púrpura o rojo, bandas mediapetalinas discoloras; lóbulos con margen entero, ápice obtuso o agudo, con o sin mucrones; tubo de la corola 1,61,7 × 1,2 cm; limbo de 3,7-5,4 mm diám., nervaduras conspicuas; androceo de 5 estambres, inclusos, anteras torcidas en la antesis; gineceo ovado, estigmas 2, esféricos. Fruto dehiscente, globoso o deprimido globoso, de 15-20 mm diám., superficie del exocarpo ligeramente papiloso; sépalos persistentes y acrescentes en el fruto; sépalo acrescente más externo 25-30 ×9-12 mm, perpendiculares al eje, de dehiscencia loculicida, 4 lóculos. Semillas ovoides o trígonas, 4 por fruto, de 6-12 mm de largo, glabras.

Material seleccionado: ARAGUA: Maracay, El Limón, 8.V.1957, fl., B. Trujillo 3385 (MY). BOLÍVAR: Municipio Roscio, El Callao, alrededores del galpón., V.1986, fl., E. Sanoja 1177 (PORT). FALCÓN: Sierra de Chichiriviche a $4 \mathrm{~km}$ arriba de Morrocoy, 24.XI.1975, fl., R. Smith V7966 
(VEN). MÉRIDA: arriba de afluente de Río Chama, en la carretera a Chiguará, 31.VIII.1966, fl., J. Steyermark \& M. Rabe 97027 (VEN). MONAGAS: creciendo como maleza en áreas verdes de Maturín, 4.II.2008, Ferrer-Pereira 317, 318 (VEN). NUEVA ESPARTA: Isla de Margarita, 2.XI.1980, fr., J. Hoyos \& F. Delascio 4555 (VEN). PORTUGUESA: Distrito Guanare, Guanare, 16.II.1985, fl., G. Aymard 3416 (PORT). SUCRE: Sabilar-Cumaná, 1.XII.1982, fl., L. Cumaná 1091 (MY, PORT, VEN). VARGAS: creciendo como maleza en áreas verdes de Caraballeda, 6.IX.2008, fl., H. Ferrer-Pereira \& P. Gauna 768 (VEN). ZULIA: Distrito Colón, carretera Puerto Chama - Concha, entre km 14 y 25 al NO de Puerto Chama, 11.V.1978, fl., G. Bunting \& P. Drummond 6323 (VEN).

A pesar de mostrar una distribución amplia, esta especie ha sido colectada con más frecuencia al norte del Orinoco, desde el nivel del mar hasta los 700 m (Fig. 6). Las flores blancas con el centro púrpura así como las hojas palmatipartidas con margen irregular son los caracteres que mejor distinguen a $M$. dissecta.

5. Merremia macrocalyx (Ruiz \& Pav.) O'Donell, Lilloa 6: 506. 1941. Convolvulus macrocalyx Ruiz \& Pav., Fl. peruv. 2: 10. 1799.

Figs. 4e, 5

Convolvulus glaber Aubl., Hist. pl. Guiane 1: 138, t. 53. 1775.

Sufrútices o hierbas, volubles o postradas; tallos teretes, 1,8-3,5 mm diám., ligeramente costulados. Hojas compuestas, 5-folioladas; pecíolos poligonales ocasionalmente teretes, de 8-42 × 0,6-1,1 mm; peciólulos ausentes. Folíolos elípticos, rara vez ovados, frecuentemente concoloros, base atenuada, ángulo basal agudo algunas veces obtuso, margen entero, ápice a menudo atenuado, menos frecuentemente agudo o acuminado, con mucrones; folíolo central 3,26-9,7 × 1,02-3,44 cm; folíolos laterales 2,46-6,36 ×0,78-2,38 cm, nerviación broquidódroma rara vez eucamptódroma. Tallos y pecíolos glabros. Láminas foliares generalmente glabras, rara vez con tricomas. Inflorescencias en dicasios compuestos o dicasios, 3-13 flores, con 34 grados de ramificación, que alcanzan $88-252 \mathrm{~mm}$ de largo; pedúnculo terete, rara vez poligonal, de 7,35-210,7 × 1-1,8 mm, no ensanchado en la base; pedúnculos y pedicelos glabros; brácteas caducas, ovadas; bractéolas 2, persistentes ocasionalmente caducas, ovadas, rara vez elípticas. Flores 2,64-5,98 cm de largo; pedicelos poligonales menos frecuentemente teretes, 10,7-26×0,5-1,1 mm; cáliz de 5 sépalos, glabros, distinguidos en dos series, libres entre sí, prefloración imbricada, elípticos, ocasionalmente ovados, generalmente obtusos en la base algunas veces agudos, margen entero con consistencia membranácea, rectos, ápice obtuso, rara vez atenuado, con mucrones; sépalo más externo 10,4-20,9 ×3,2-7 mm, sépalo más interno 13,5-23 × 3,7-7 mm, nervaduras inconspicuas; corola de 5 pétalos, glabra, blanca, con margen entero o lobulado, con prefloración imbricada; bandas mediapetalinas concoloras, muy raras veces discoloras; lóbulos con margen entero, ápice obtuso rara vez agudo, frecuentemente sin mucrones, de 9,6 × 10,05 mm; tubo de la corola de $2,02-4,5 \times 0,72-1,88 \mathrm{~cm}$, limbo de hasta 15-38,7 mm diám., nervaduras más frecuentemente conspicuas; androceo de 5 estambres, adnatos a la corola, libres entre sí, inclusos, insertos en el tercio inferior de la corola, filamentos anisodínamos $(2+2+1)$, con tricomas distribuidos en el tercio basal, anteras triangulares, dorsifijas, frecuentemente torcidas en la antesis; gineceo sincárpico, disco anular, ovario ovado, glabro, estigmas 2, placentación central basal, con 1 óvulo por lóculo. Fruto dehiscente, globoso, de 6-13 mm diám., superficie del exocarpo lisa; sépalos persistentes y acrescentes en el fruto; sépalo acrescente más externo 17,8-26,7 ×5,1-7 mm, sépalo acrescente más interno 20,4-27 ×5,4-8,4 mm, generalmente perpendiculares al eje (patentes), con 2 o 4 septos, de dehiscencia septicida, 4 lóculos. Semillas trígonas, 4 por fruto, de 3,1-3,5 $\mathrm{mm}$ de largo, con tricomas filiformes, distribuidos en toda la superficie.

Material seleccionado: AMAZONAS: San Pedro Cataniapo-San Pablo Cataniapo, Middle Cataniapo river (below Salto Nieve), both side (San Pedro right bank, San Pablo left bank), 17.II.1987, fl., S. Zent 0287-17 (VEN). ANZOÁTEGUI: Distrito Libertad, road from El Vigía to Buenos Aires, 8-15 km ENE of Bergantín, 27.XI.1981, fl., G. Davidse \& A. González 19471 (VEN). ARAGUA: Parque Henri Pittier, 26.XI.1976, fl., H. Rodríguez 652 (MY). BOLÍVAR: 5-18 km al S de El Dorado, 1.IV.1985, fr., $B$. Holst et al. 2023 (VEN). CARABOBO: alrededores de La Cumbre, Canoabo, s.d., fl., B. Trujillo 5755 (MY). COJEDES: Cerro Azul, Fila La Blanquera, al NE de la Sierra, 1.II.1976, fl., Delascio 4157 (VEN). DELTA AMACURO: cercanías Castillos de Guayana, 19.XII.1978, fl., N. Xena 256 (VEN). DISTRITO CAPITAL: El Junquito, 26.III.1946, fl., E. Killip \& E. Rohl 37201 (VEN). FALCÓN: Distrito Democracia, alrededores de Avaria y ladera oriental del Cerro Montero, 2-5.III.1972, fl., G. Agostini \& T. de Agostini 1054 (VEN). MÉRIDA: on slope above dam site on Río Caparo, 31 km ESE of Santa Bárbara, 9.III.1980, fr., R. Liesner \& A. González 9266(VEN). MIRANDA: Parque Nacional de Guatopo, N of Altagracia de Orituco, 17.II.1979, fl., A. Gentry \& R. Troth 24825 (VEN). MONAGAS: moist open area of floodplain of the Río Guarapiche $c a .2 \mathrm{~km}$ SSW of Jusepín, 22.II.1967, fl., R. Pursell et al. 8125(VEN). PORTUGUESA: Distrito Araure, carretera Hoja BlancaGuayabal-El Rechazo, 9.III.1988, fl., N. Cuello \& E. Cuello 
58(VEN). SUCRE: 1-2 km above Mochima (between Puerto La Cruz and Cumaná), 17.XII.1973, fl., G. Davidse 5052 (VEN). TÁCHIRA: carretera San Cristóbal, Parque Cazadero pasando Palo Grande, en el cruce a Cazadero, 26.VI.1997, fl., Trujillo et al. 24413 (MY). VARGAS: camino Los Castillitos-El Rincón, S de Maiquetía, vertiente N de la Cordillera de La Costa, 22.II.1971, fr., G. Morillo \& B. Manara 510 (VEN). YARACUY: along road between Salom (E of Nirgua) and Temerla, 7,4 km N of Salom, 3.III.1993, fr., T. Croat 74407(VEN).ZULIA: Distrito Perijá, alrededores de la Estación Hidrológica Aricuaisá-Pie de Monte, 25.II.-3.III.1982, fl., G. Bunting et al. 11066 (VEN).

Una de las especies más colectadas en el país, mostrando una distribución amplia la cual cubre todos los estados venezolanos (Fig. 5) y varias formas de vegetación asociadas; generalmente por encima de los $100 \mathrm{~m}$ hasta los $1.400 \mathrm{~m}$. Puede reconocerse por la condición glabra o glabrescente de las estructuras de la planta, inflorescencias generalmente formando dicasios compuestos y la acrescencia de sépalos reflexos durante la fructificación cuya longitud puede ser hasta cuatro veces el ancho.

6. Merremia maypurensis Hallier f., Bot. Jahrb. Syst. 16: 552. 1893.

Figs. 4f, 7

Hierbas o sufrútices, volubles; tallos teretes, de 0,5-0,9 mm diám.; lisos. Hojas simples, enteras; pecíolos teretes, de 4,3-13,4 ×0,1-0,5 mm; láminas foliares ovadas, generalmente concoloras, base peltada, ángulo obtuso, margen entero, ápice agudo a acuminado, con mucrones, 3,49-5,60 × 0,39-1,12 $\mathrm{cm}$, venación broquidódroma a eucamptódroma. Tallos y pecíolos siempre glabros, raras veces con tricomas filiformes, blancos, erectos, con cobertura laxa, distribuidos en el tercio basal; láminas foliares glabras. Inflorescencias reducidas, unifloras, hasta 65,8 mm de largo; pedúnculo terete, 16,5-33,1 ×0,4$0,7 \mathrm{~mm}$, no ensanchado en la base; pedúnculos y pedicelos glabros, raras veces con tricomas en la zona basal, translúcidos o blancos, filiformes, erectos, cobertura laxa; brácteas generalmente ausentes, cuando presentes ovadas; bractéolas 2, caducas. Flores hasta 2,9 cm de largo; pedicelos teretes, hasta $8,7 \times 1,3$ mm; cáliz de 5 sépalos, glabros, distinguidos en dos series, libres entre sí, con prefloración imbricada, elípticos a ovados, obtusos en la base, raramente agudos, a menudo rectos, pocas veces cóncavos, margen entero con consistencia membranácea, ápice obtuso a agudo, con mucrones; sépalos más externos 5,5-9,9×4-6 mm, sépalos más internos $10-11,5 \times 2,25-5 \mathrm{~mm}$, nervaduras inconspicuas; corola de 5 pétalos, blanca a blancocremosa, margen entero, prefloración valvada- induplicada, bandas mediapetalinas concoloras a discoloras; lóbulos 1,3-2×5,7-6 mm, margen entero, ápice obtuso a agudo, con mucrones; tubo de la corola hasta 2,2 $\times 0,8 \mathrm{~cm}$; limbo hasta $28 \mathrm{~mm}$ diám., glabra o raras veces con tricomas en la zona mediapetalina, blancos, filiformes a ascendentes, con cobertura medianamente densa, nervaduras conspicuas; androceo de 5 estambres, libres entre sí, inclusos, adnatos a la corola, insertos en el tercio inferior de la corola, generalmente didínamos $(3+2)$, filamentos 2,2-5,4 mm de largo, glabros o con tricomas distribuidos en el tercio basal, anteras oblongas, de 2-4 × 0,6-0,9 mm, basifijas, con dehiscencia introrsa, a menudo torcidas en la antesis; gineceo sincárpico, 2 carpelos, 2 lóculos, disco anular, ovario elíptico, glabro; estigmas 2, esféricos. Fruto dehiscente, globoso, 10-12 mm diám, 1 lóculo; superficie del exocarpo lisa a rugosa; sépalos persistentes, no acrescentes en el fruto; sépalos persistentes más externos hasta 9,3 $\times$ 3,5 mm, sépalos persistentes más internos hasta 12 mm de largo, paralelos al eje. Semillas ovoides, 1 por fruto, $7 \mathrm{~mm}$, con tricomas o glabras.

Material seleccionado: AMAZONAS: Departamento Atures, carretera Puerto Ayacucho hacia El Burro, 1 km, laja al lado oriental de la carretera, atrás de una Estación Militar, 2.X.1993, fl. y fr., A. Gröger \& S. Llamozas 1145 (VEN).

Generalmente creciendo en sabanas y áreas arbustivas adyacentes a afloramientos graníticos. En Venezuela, se encuentra restringida al área de la Guayana, específicamente en el Estado Amazonas, al sureste del río Orinoco (Fig. 7), entre 75 y 150 m.

7. Merremia nervosa Pittier, J. Wash. Acad. Sci. 17:286. 1927.

Fig. 5

Merremia asterotricha Pittier, J. Wash. Acad. Sci. 17: 286. 1927.

Hierbas o sufrútices, principalmente volubles, ocasionalmente erectas; tallos teretes, 1,3-2,7 mm diám., lisos. Hojas compuestas, 3-folioladas; pecíolos teretes, raras veces poligonales, 12,8-94,0 × 0,9-2,8 $\mathrm{mm}$; peciólulos teretes, $0,5-7,0 \times 0,6-1,4 \mathrm{~mm}$; folíolos elípticos a ovados, rara vez obovados, discoloros, base atenuada a redondeada, ángulo basal obtuso a agudo, margen entero, ápice agudo a obtuso, con mucrones; folíolo central 3,64-13,0 × 1,90-6,38 cm; folíolos laterales hasta $9,46 \times 4,54 \mathrm{~cm}$, nerviación craspedódroma simple a eucamptódroma. Tallos, pecíolos y peciólulos con tricomas estrellados, amarillentos, translúcidos o blancos, erectos, con cobertura densa, distribuidos en toda la extensión; láminas foliares con tricomas translúcidos o amarillentos, estrellados, erectos, con cobertura laxa 
en la cara adaxial y medianamente densa a densa en la cara abaxial. Inflorescencias en dicasios o dicasios compuestos, hasta 14 flores, 4 grados de ramificación, hasta 17,5 cm de largo; pedúnculo terete o poligonal, 26,4-113,2 × 1-2 mm, no ensanchado en la base; pedúnculos y pedicelos con tricomas, en toda la superficie, amarillentos, translúcidos o blancos, estrellados, erectos, con cobertura densa; brácteas persistentes o caducas, de contorno ovado o elíptico; bractéolas 2, generalmente persistentes, ovadas a lineares. Flores 1,9-3,28 cm de largo; pedicelos teretes, hasta $17,3 \times 1,41 \mathrm{~mm}$; cáliz de 5 sépalos, distinguidos en dos series, libres entre sí, con tricomas amarillentos, translúcidos o blancos, estrellados, erectos, en el margen y en toda la superficie de la cara abaxial, cobertura medianamente densa a densa, con prefloración imbricada, a menudo elípticos a ovados, obtusos en la base, margen entero con consistencia membranácea, rectos, ocasionalmente cóncavos, ápice acuminado, agudo u obtuso, con mucrones; sépalos más externos 7-10 $\times 3,2-5,8$ mm, sépalos más internos 10-11,7×3,2-5,5 $\mathrm{mm}$, nervaduras inconspicuas; corola de 5 pétalos, glabra, blanca, margen entero o lobulado, con prefloración valvada-induplicada; bandas mediapetalinas concoloras; lóbulos 4-5 × 10-13,8 $\mathrm{mm}$, ápice frecuentemente redondeado hasta obtuso o agudo, sin mucrones; tubo de la corola hasta 2,15 $\times$ 1,08 cm diám.; limbo de hasta 34 mm diám., nervaduras conspicuas o inconspicuas; androceo de 5 estambres, adnatos a la corola, libres entre sí, inclusos, insertos en el tercio inferior de la corola, anisodínamos $(2+2+1)$, filamentos 5-14 mm de largo, glabros o con tricomas distribuidos en el tercio basal, anteras elípticas a oblongas, 2,2-4,5 × 1,0-1,4 mm, dorsifijas, dehiscencia introrsa, torcidas en la antesis; gineceo sincárpico, 2 carpelos, 4 lóculos, disco anular, ovario globoso, con tricomas estrellados, translúcidos o amarillentos, con hasta 16 brazos, cobertura medianamente densa a densa, estigmas 2 , esféricos, 1 óvulo por lóculo con placentación central basal. Fruto dehiscente, globoso, 8,0-8,8 mm diám., superficie del exocarpo lisa, glabra; sépalos persistentes y acrescentes en el fruto; sépalos acrescentes más externos hasta 5,8 $\times 4,3 \mathrm{~mm}$, sépalos acrescentes más internos hasta 7,7 ×4,8 mm, paralelos al eje, con 2 septos, dehiscencia septicida, 4 lóculos. Semillas trígonas, 4 por fruto, 4,4 mm, con tricomas. Material seleccionado: LARA: Cerro Gordo, cerca de Barquisimeto, 1.X.1926, fl., J. Saer 294 (VEN, holótipo de $M$. nervosa); Distrito Palavecino, laderas pendientes entre Terepaima y Cabudare, mirando al NO, 510.VIII.1970, fl., J. Steyermark et al. 103644 (VEN); Río
Turbio, cerca de Barquisimeto, 1.VI.1925, fl., J. Saer 248 (VEN, holótipo de M. asterotricha). YARACUY: cerca de Cañada y Lomas, 1.IV.1980, st., N. Ramírez 361 (VEN).

Generalmente asociada a zonas boscosas de los estados Lara y Yaracuy (Fig. 5), entre 500 y $1.000 \mathrm{~m}$. Endémica de Venezuela, es fácilmente reconocible por la presencia de tricomas estrellados, a menudo de color blanquecino y con muchos brazos, en todas las estructuras de la planta, a excepción de la corola y los sépalos más internos.

8. Merremia quinquefolia (L.) Hallier f., Bot. Jahrb. Syst. 16: 552. 1893. Ipomoea quinquefolia L., Sp. pl. 1: 162.1753.

Figs. 7, 8a

Convolvulus hispaniolae Spreng., Syst. veg. (ed. 16) 1:590. 1825.

Hierbas volubles, rara vez sufrútices; tallos teretes, $0,9 \times 2,7 \mathrm{~mm}$ diám., ligeramente costulados. Hojas compuestas 5-folioladas; pecíolos teretes o poligonales, 7-35 ×3,0-1,92 mm. Folíolos elípticos u obovados, concoloros, base atenuada, ángulo basal agudo, margen aserrado, ápice generalmente agudo ocasionalmente obtuso o acuminado, con mucrones, folíolo central 1,15-3,86 × 0,36-1,36 cm, folíolos laterales hasta $0,73-2,50 \times 0,34-1,14 \mathrm{~cm}$, nerviación craspedódroma simple raras veces broquidódroma. Tallos y pecíolos glabros o con tricomas filiformes, translúcidos a veces amarillentos, erectos, con cobertura laxa a medianamente densa, distribuidos en toda la extensión. Láminas foliares glabras. Inflorescencias generalmente en dicasios pocas veces en monocasios o reducidas, 1-3 flores rara vez 9, que alcanzan 38-64,4 mm de largo; pedúnculo terete, 0,62,5× 0,4-1 mm, sin ensanchamiento en la base. Pedúnculos y pedicelos con tricomas frecuentemente en la zona distal, algunas veces en la zona basal y ocasionalmente en la zona media o en toda la superficie, translúcidos o amarillentos, filiformes y glandulares, erectos, con cobertura medianamente densa, a veces laxa. Brácteas y bractéolas 2, persistentes, elípticas y algunas veces ovadas. Flores 1,1-3,4 cm de largo; pedicelos teretes rara vez poligonales, 2,7-15 ×0,3-1 mm; cáliz de 5 sépalos, glabros, distinguidos en dos series, libres entre sí, prefloración imbricada, elípticos a ovados, obtusos en la base, margen entero con consistencia membranácea, rectos, ápice obtuso a agudo, algunas veces redondeado, con mucrones; sépalo más externo de 4-7×1,9-4,7 mm, sépalo más interno de 5-13×1,6-3 mm, nervaduras inconspicuas; corola de 5 pétalos, margen entero, con prefloración imbricada, blanca o blanco-cremosa, glabra o con tricomas hirsutos, blancos, filiformes distribuidos en el tercio apical, con cobertura medianamente densa; 
bandas mediapetalinas generalmente concoloras; lóbulos 1,5-2,6 × 3,7-4,2 mm, margen entero, ápice redondeado u obtuso, con mucrones; tubo de la corola de 0,7-1,9×0,3-1,17 cm; limbo de 10-19,4 mm diám., nervaduras conspicuas; androceo de 5 estambres, adnatos a la corola, libres entre sí, inclusos, insertos en el tercio inferior de la corola, didínamos, filamentos con tricomas distribuidos en el tercio basal, anteras oblongas, basifijas, generalmente no torcidas en la antesis; gineceo sincárpico, de 204 carpelos, con 2 4 lóculos, disco anular, ovario globoso, glabro; estigma aparentemente 1, esférico, placentación central basal, 2 óvulos por lóculo. Fruto dehiscente, globoso, de 510,2 mm diám., con 3 a 4 septos, de dehiscencia loculicida, 4 lóculos; superficie del exocarpo lisa, glabra; sépalos persistentes y acrescentes en el fruto, sépalo acrescente más externo de 3-10,4×2,2-5 mm, sépalo acrescente más interno 6-9,7 × 2,5-4,9 mm, paralelos al eje. Semillas trígonas, 3 a 4 por fruto, de 4,5-8,6 mm de largo, con tricomas color claro, translúcidos.

Material seleccionado: ANZOÁTEGUI: A orillas de la carretera entre Puerto Píritu y Puerto La Cruz, a $400 \mathrm{~m}$ de Puerto Píritu, 3.IV.2010, fl., H. Ferrer-Pereira et al. 770. ARAGUA: Parque Nacional Henri Pittier, 25.I.1973, fr., G. Morillo \& B. de Morillo 2959 (VEN). FALCÓN: Mirador de Tocópero, 3.V.2008, fl. y fr., H. Ferrer-Pereira \& S. Nozawa 756 (VEN). TÁCHIRA: San Antonio del Táchira, alrededores del Aeropuerto Internacional General Juan Vicente Gómez, 31.XII.2005, fl., S. Nozawa 953A (VEN). LARA: alrededores del Tocuyo, 19.II.1950, fl., Velasco 238 (MY). MIRANDA: Ocumare del Tuy, 28.IV.1951, fr., E. Foldats 770 (MY). SUCRE: Distrito Benítez, Serranía de La Paloma, forested slopes along Río Frio, between Ajíes and Guariquén, 8,5 km S of Ajíes, 19.II.1980, fr., $J$. Steyermark et al. 121399 (VEN). VARGAS: alrededores de Caraballeda, cerca de las casas, 1-29.II.1960, fr., $L$. Aristeguieta 4105 (VEN). YARACUY: Hacienda Iboa cerca de San Pablo, 13.I.1928, fr., H. Pittier 12607(VEN). ZULIA: Municipio Maracaibo, adyacencias de la Facultad, 29.IX.2004, fr., M. Frontado MF-014 (VEN).

Restringida al norte del Orinoco, más frecuentemente hacia la zona costera. Ocupa los hábitats secos, por debajo de los $200 \mathrm{~m}$, a menudo próximos a la costa. En los estados Lara, Táchira, Yaracuy y Aragua se localiza hacia las regiones más áridas (Fig. 7). A diferencia de M. cissoides, los especímenes revisados de $M$. quinquefolia presentan sépalos con ángulo obtuso los cuales se hacen más anchos a medida que se desarrolla el fruto llegando a cubrirlo. Además, los tricomas glandulares sólo se encuentran en el pedúnculo y/ o los sépalos más externos, mientras que en $M$. cissoides se restringen a los tallos, pecíolos y hojas.

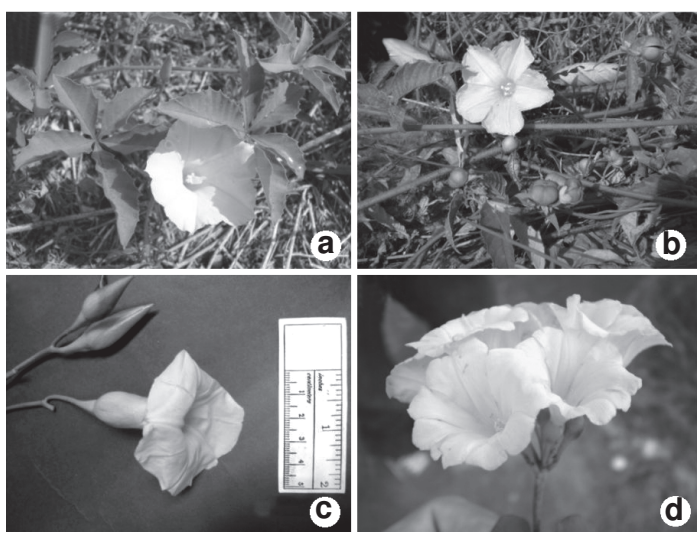

Figura 8 - Especies de Merremia en Venezuela: a. $M$. quinquefolia; b. M. ternifoliola; c. M. tuberosa; d. M. umbellata. Figure 8-Merremia species from Venezuela: a. M. quinquefolia; b. M. ternifoliola; c. M. tuberosa; d. M. umbellata.

9. Merremia ternifoliola Pittier, Bol. Soc. Venez. Ci. Nat. 8: 142. 1943.

Figs. 5, $8 \mathrm{~b}$

Hierbas, generalmente volubles, algunas postradas; tallos teretes, $0,2-1,5 \mathrm{~mm}$ diám., lisos, rara vez ligeramente costulados, glabros o con tricomas en toda la superficie o en algunos casos sólo en los nudos, filiformes, translúcidos, algunos amarillentos, raras veces blancos, unicelulares, generalmente erectos, ocasionalmente ascendentes, cobertura con frecuencia medianamente densa, a veces laxa, raro densa. Hojas compuestas, 3folioladas; pecíolos teretes, $2-26 \times 0,1-0,9 \mathrm{~mm}$, generalmente con tricomas, raras veces glabros, indumento en toda la extensión, pocas veces en el tercio basal, tricomas translúcidos, algunos casos amarillentos o blancos, filiformes, unicelulares, erectos, raramente hirsutos, cobertura generalmente medianamente densa, pocas laxa o densa; peciólulos generalmente ausentes, raro presentes, teretes, $2,5 \times$ $0,5 \mathrm{~mm}$, con tricomas en toda la superficie, translúcidos, filiformes, unicelulares, erectos, cobertura medianamente densa; folíolos ovados, generalmente concoloros, base redondeada, pocas cordadas, ángulo basal obtuso o agudo, margen generalmente entero o aserrado, algunos ondulados o crenado, ápice agudo, pocos atenuado, mucronado; folíolo central 16-22 × 0,3-2,1 cm; folíolos laterales $0,65-3,2 \times 0,24-1,4 \mathrm{~cm}$, nerviación broquidódroma, algunas veces craspedódroma simple, con tricomas en toda la superficie de la lámina, tricomas translúcidos, a veces blancos o amarillentos, filiformes, unicelulares, adpresos o ascendentes, con cobertura laxa o medianamente densa en ambas caras. Inflorescencias reducidas a 1 flor o en cincinos 
compuestos, raramente dicasios, de 2 hasta 9 flores, en estos casos con 1 a 4 grados de ramificación, 3,9$61 \mathrm{~mm}$ de largo; pedúnculo terete, no ensanchado en la base, 3-35 ×0,2-5 mm, generalmente con tricomas, a menudo presentes en la zona basal o en toda la superficie, translúcidos, amarillentos o blancos, filiformes, unicelulares, erectos, a veces ascendentes o hirsutos, con cobertura medianamente densa, a veces laxa o densa; brácteas persistentes, raro ausentes, ovadas; bractéolas persistentes, 1 о 2, ovadas. Flores de 2,2-3,5 cm de largo; pedicelos generalmente presentes, teretes, $0,5-65 \times 0,1-4 \mathrm{~mm}$, glabros, raro con tricomas en toda la superficie, en este caso blancos, filiformes, unicelulares, hirsutos, con cobertura densa; cáliz de 5 sépalos, distinguidos en dos series, libres entre sí, raro fusionados, prefloración imbricada, frecuentemente ovados, base obtusa, margen entero, con consistencia membranácea, rectos, glabros, ápice obtuso o agudo, con mucrones, sépalos más externos 3,5-8×1-4 mm, sépalos más internos $13 \times 6 \mathrm{~mm}$, algunos con tricomas en toda la superficie de la cara abaxial, tricomas translúcidos, a veces blancos o amarillentos, filiformes, unicelulares, hirsutos o ascendentes, con cobertura medianamente densa, a veces laxa, nervaduras inconspicuas, a veces conspicuas; corola de 5 pétalos, blanca o blanco-cremosa, glabros, margen entero o lobulado, prefloración valvada-induplicada, bandas mediapetalinas inconspicuas; lóbulos ovados, margen crenado o entero, ápice obtuso, a veces agudo o redondeado, sin mucrones, $12 \times 4-12 \mathrm{~mm}$, tubo de la corola 14,5-20×7-14 mm; limbo 25-34,5 mm diám., nervaduras conspicuas; androceo de 5 estambres, libres entre sí, inclusos, insertos en el tercio inferior de la corola, didínamos, filamentos 9-15 mm de largo, con tricomas distribuidos en el tercio basal, anteras oblongas, $1,5-5,5 \times 0,5-1,5 \mathrm{~mm}$, basifijas, con dehiscencia introrsa, por lo general torcidas en la antesis; gineceo con 4 lóculos, a veces 3; ovario ovado, glabro, disco ausente; estigmas 2, esféricos, 1 óvulo por lóculo, en ocasiones se observa un ápice discoide en el pedicelo luego que cae la flor. Fruto dehiscente, globoso, 7-13 mm diám., superficie del exocarpo lisa; sépalos persistentes, no acrescentes en el fruto, sépalos persistentes más externos 3-6× 2-4 mm, sépalos persistentes más internos 6-14×4$7 \mathrm{~mm}$, paralelos al eje, con 2-3 septos, dehiscencia loculicida, 3 lóculos. Semillas ovoides, 2-3 por fruto, $5,5 \mathrm{~mm}$ de largo, con tricomas filiformes distribuidos en toda la superficie.

Material seleccionado: BOLÍVAR: en terreno cultivado de Ciudad Bolívar, 21.IV.1940, L. Williams 12862 (VEN, parátipo); Ciudad Guayana, cerca de la autopista a unos
$500 \mathrm{~m}$ antes del Puente Orinoquia en sentido S-N, 26.I.2008, fl., Y. Vivas et al. 1722 (VEN). GUÁRICO: Sabanetas cerca de Santa María de Ipire, 9.I.1941, $H$. Pittier 14728 (VEN, holótipo); roadside $c a .35 \mathrm{~km} \mathrm{~N}$ of Calabozo, 7.VI.1967, fl. y fr., K. Roberston \& D. Austin 182 (VEN). MONAGAS: along Río Amana, NE of Santa Bárbara, 13.VII.1967, fl., R. Pursell et al. 8722 (VEN).

Común en el sur del Orinoco, pocas veces colectada al norte (Fig. 5), pero siempre cerca a las riberas del río y por debajo de los $250 \mathrm{~m}$ s.n.m. Puede reconocerse por las hojas trifolioladas y los largos tricomas filiformes y blanquecinos que se desarrollan en las zonas más viejas del tallo en crecimiento.

10. Merremia tuberosa (L.) Rendle, Fl. trop. Afr. 4(2): 104. 1905. Ipomoea tuberosa L., Sp. pl. 1: 160. 1753.

Figs. 6, 8c

Sufrútices volubles; tallos teretes, 2,5-9,8 mm diám., lisos o ligeramente costulados. Hojas simples, palmatisectas; pecíolos teretes o algunos aplanados, 48-135 × 1,0-1,8 mm; láminas foliares 7-11 ×9$18,6 \mathrm{~cm}$, obovadas u ovadas, concoloras, rara vez discoloras; base auriculada, algunas veces redondeadas, ángulo obtuso, rara vez agudo; margen entero o aserrado (en especimen juvenil); ápice agudo o atenuado, con mucrones; nerviación palinactinódroma. Tallos y pecíolos o peciólulos glabros, láminas foliares glabras. Inflorescencias 14,4$197,5 \mathrm{~mm}$ de largo, generalmente reducidas a 1 flor, raras veces en monocasios o dicasios compuestos de 2-10 flores, 1-4 grados de ramificación; pedúnculo terete, por lo general no ensanchado en la base, 52$147 \times 1,6-3,5 \mathrm{~mm}$, glabros; brácteas caducas, en este caso elípticas cuando persistentes; bractéolas persistentes o caducas, lineares, 5-5,5 $\mathrm{mm}$ de largo; pedicelos teretes, 6-25 × 0,5-1 mm. Flores hasta 9,2 cm de largo; cáliz de 5 sépalos, glabros, distinguidos en dos series, connados en la base, con prefloración contorta, ovados, obtusos en la base, margen entero con consistencia membranácea, rectos, nervaduras conspicuas, ápice redondeado, con mucrones; sépalos más externos 23-30×10-14 mm, sépalos más internos 21-25 ×6,5-10 mm, nervaduras conspicuas; corola de 5 pétalos, amarilla, glabra, margen lobulado o entero, con prefloración imbricada; limbo, tubo de la corola y garganta amarilla, bandas mediapetalinas inconspicuas; lóbulos obovados, margen entero, ápice redondeado, sin mucrones, hasta $8,3 \times 13 \mathrm{~mm}$; tubo de la corola hasta $4,2 \times 1,5 \mathrm{~cm}$, nervaduras conspicuas; androceo de 5 estambres, adnatos a la corola, libres entre sí, inclusos, insertos en el tercio inferior de la corola, anisodínamos $2+2+1$, filamentos de 6-14 mm de largo, con tricomas, distribuidos en el 
tercio basal, anteras oblongas, de 5-6 × 1-1,5 mm, basifijas, con dehiscencia introrsa, torcidas en la antesis; gineceo de 4 carpelos, con 4 lóculos, disco anular, ovario globoso, glabro; estigmas 2, esféricos, placentación axilar, con 1 óvulos por lóculo. Fruto dehiscente, globoso, raramente ovado, 26,5-42 mm diám., superficie del exocarpo lisa; sépalos persistentes y acrescentes en el fruto; sépalos acrescentes más externos 39-52,7×24-43 mm; sépalo acrescente más interno 35-56 × 25-40 mm, paralelos al eje, con 4 septos, dehiscencia septicida, 4 lóculos. Semillas trígonas, 4 por fruto, 20-27 mm de largo, con tricomas filiformes, distribuidos en toda la superficie.

Material seleccionado: ARAGUA: Autopista MaracayCaracas, entre La Victoria y Tejerías, $10 \mathrm{~km}$ al este de La Victoria, al lado del río al norte de la carretera, 26.XI.1969, st., G. Bunting \& G. Ferrari 4207A, 4207B (VEN, MY). DISTRITO CAPITAL: Puerto La Cruz, 3.I.1929, fl., E. Holt 170, 207 (VEN). TÁCHIRA: Parque Nacional Tamá, sector Río Negro, camino Troncal 5, Santa Ana, por la Quebrada del Río Negro, 15.IX.1998, fr., Stergios et al. 17821 (PORT). VARGAS: Quebrada Camurí, open disturbed area Camurí Grande, 28.I.1976, fl., Ch. Wood 495 (VEN). YARACUY: Distrito Bruzual, montaña de María Lionza, entre el Río Yaracuy y las faldas más bajas de la montaña, a lo largo de la Quebrada Tinaja, al E de la Quebrada Quibayo, al S de Quibayo, al S de Chivacoa, 12.III.1981, fr., J. Steyermark et al. 124982 (VEN). ZULIA: Distrito Perijá, Hacienda La Filipina, 5.XII.1976, fr., G. Ferrari \& B. Trujillo 1581 (MY).

Comúnmente colectada en el norte del país (Fig. 6), especialmente en zonas boscosas entre los 35 y $800 \mathrm{~m}$ Con porte bien desarrollado, puede producir tubérculos radicales ocasionalmente. Una de las pocas especies de Merremia en Venezuela con corola amarilla, de gran tamaño y ausencia de tricomas en todas las estructuras de la planta.

11. Merremia umbellata (L.) Hallier f., Bot. Jahrb. Syst. 16(4-5): 552. 1893. Convolvulus umbellatus L., Sp. pl. 1: 155. 1753.

Figs. 6, 8d

Convolvulus multiflorus Mill., Gard. dict. (ed. 8) 15.1768 .

Convolvulus caracassanus Willd. ex Roem. \& Schult., Syst. veg. 4: 301. 1819.

Convolvulus luteus M. Martens \& Galeotti, Bull. Acad. Roy. Sci. Bruxelles 11(2): 260. 1845.

Sufrútices, volubles; tallos teretes, $1,3-3 \mathrm{~mm}$ diám.; lisos o ligeramente costulados. Hojas simples, enteras; pecíolos teretes, 8,3-110×0,4-7 mm, láminas foliares ovadas, concoloras, de 2,87-14 × 0,84-11,9 $\mathrm{cm}$, base auriculada, rara vez cordada, ángulo obtuso o agudo, margen entero, ápice frecuentemente acuminado, ocasionalmente agudo o atenuado, con mucrones, nerviación actinódroma. Tallos y pecíolos con tricomas filiformes, blancos, rara vez amarillentos, hirsutos, rara vez adpresos o erectos, cobertura densa, medianamente densa a laxa, distribuidos en toda la extensión o algunas veces en el tercio apical. Láminas foliares pubescentes, en ocasiones glabras, tricomas frecuentemente distribuidos en toda la superficie en ambas caras, de cobertura medianamente densa en la cara abaxial. Inflorescencias en cimas umbeliformes, raras veces reducidas, 1-31 flores, frecuentemente 34 grados de ramificación, 6,6-140 mm de largo; pedúnculo terete, rara vez aplanado, 37-110×0,6-18 $\mathrm{mm}$, no ensanchado en la base; pedúnculos y pedicelos pubescentes, algunas veces glabros, tricomas en toda la superficie, blancos, rara vez translúcidos o amarillentos, filiformes, hirsutos, rara vez adpresos o ascendentes o erectos, generalmente con cobertura medianamente densa, pocas veces densa y rara vez laxa; brácteas y bractéolas caducas, raras veces persistentes, ovadas, rara vez elípticas. Flores de 1,8-3,01 cm de largo; pedicelos teretes, rara vez aplanados, $0,7-45 \times 0,7-1 \mathrm{~mm}$; cáliz de 5 sépalos, glabros, rara vez pubescentes, tricomas filiformes, blancos, erectos, con cobertura laxa, distribuidos en el tercio medio, libres entre sí, con prefloración imbricada, obovados, rara vez ovados, obtusos en la base, margen entero con consistencia membranácea, cóncavos, ápice frecuentemente obtuso, pocas veces redondeado o acuminado, con mucrones; sépalo más externo de $0,75-11 \times 0,59-35 \mathrm{~mm}$, sépalo más interno de $0,75 \times 0,5 \mathrm{~mm}$, nervaduras inconspicuas; corola con frecuencia de 5 pétalos, amarilla, con prefloración valvado-induplicada, generalmente pubescente, tricomas filiformes, hirsutos, blancos, distribuidos en el tercio apical, en la zona interpetalar, con cobertura laxa o medianamente densa, margen lobulado; bandas mediapetalinas concoloras, rara vez discoloras; lóbulos ovados a obovados, con margen entero, ápice obtuso, rara vez redondeado, de 1-3,4 mm × 3-9 mm; tubo de la corola de $1-2,59 \times 0,57-0,9 \mathrm{~cm}$; limbo de 1,23-23,7 mm diám., nervaduras a menudo conspicuas, rara vez inconspicuas; androceo de 5 estambres, adnatos a la corola, libres entre sí, inclusos, insertos en el tercio superior de la corola, rara vez en el inferior, isodínamos o didínamos, filamentos de $2-5 \mathrm{~mm}$ de largo, glabros o con tricomas distribuidos en el tercio basal, anteras ovadas o triangulares, rara vez elípticas, 3-4 $\mathrm{mm} \times 1 \mathrm{~mm}$, dorsifijas, con dehiscencia extrorsa, no torcidas en la antesis; gineceo sincárpico, con 2 lóculos, disco anular, ovario globoso, glabro; estigmas 2 , frecuentemente esféricos, placentación central libre, con 2 óvulos por lóculo. Fruto dehiscente, globoso, 8-13 mm diám., superficie del exocarpo lisa; sépalos persistentes y acrescentes en el fruto, sépalo 
acrescente más externo 7-12,3 ×6,3-18 mm, sépalo acrescente más interno 6-11,7 ×5-7 mm, paralelos al eje, con 1 septo, rara vez 2 , de dehiscencia septicida, 2 lóculos. Semillas trígonas, $2-4$ por fruto, de 4-9,4 $\mathrm{mm}$ de largo, con tricomas filiformes, marrones, en toda la superficie.

Material seleccionado: AMAZONAS: Departamento Atures, alrededores de la Urbanización Simón Bolívar y Chaparralito de Puerto Ayacucho, 1.I.-31.III.1986, fl. y fr., F. Guánchez \& E. Melgueiro 4192 (VEN). APURE: 42 km NE of Mantecal along highway to San Fernando de Apure, 9.XI.1973, fl., G. Davidse et al. 3911 (VEN). ARAGUA: Parque Nacional Henri Pittier, 25.I.1973, fr., G. Morillo \& B. Morillo 2957 (VEN). BARINAS: Distrito Barinas, Km 4 de Barinas hacia El Corozo, 21.I.1982, fr., E. Rutkis 370(VEN). BOLÍVAR: pica Caicara del Orinoco-San Juan de Manapiare, Río Suapure, $202 \mathrm{~km}$ al S de Caicara, 1-31.III.1975, fl., $F$. Delascio \& R. López 2819 (VEN). CARABOBO: Puerto Cabello, 1.I.1971, fl., T. di Genova s/n (VEN 82881). COJEDES: Distrito San Carlos, entre Los Chupones y Las Piedras, vía La Sierra, 29.I.1987, fl. y fr., F. Delascio \& $R$. López 12975 (VEN). DELTA AMACURO: Departamento Tucupita, 13-14 km SE of Piacoa, along a trail to the Río San José, 27.III.-2.IV.1979, fl., G. Davidse \& A. González 16468 (VEN). DISTRITO CAPITAL: Puerto La Cruz, 31.XII.1928, fl., E. Holt 159 (VEN). FALCÓN: Distrito Colina, bosque a lo largo del Río Ricoa, S de Las Dos Bocas (sitio de represa), 11.II.1977, fl. y fr., J. Steyermark \& A. González 113611 (VEN). GUÁRICO: márgenes del Río Cura, cerca de Camatagua, 1-28.II.1966, fr., L. Aristeguieta 5969 (VEN). LARA: entre Yaritagua y Duaca, 1.I.1969, fr., Saer 347(VEN). MÉRIDA: Palmarito, 04.XII.1967, fl., S. López-Palacios 1786 (VEN). MIRANDA: Distrito Guaicaipuro, Cordillera de La Costa, Serranía del Interior, vertiente N, $6 \mathrm{~km}$ al S del pueblo Altagracia de La Montaña, cuenca de la Quebrada Agua Fría, 3.II.2002, fl., W. Meier \& S. Nehlin 914 (VEN). MONAGAS: floodplain of Río Guarapiche, $c a$. $2 \mathrm{~km}$ SSW of Jusepín, 1.III.1967, fl., R. Pursell et al. 8201 (VEN). PORTUGUESA: Municipio Tucupido, camino entre Tucupido y la represa del Río Tucupido, 2.II.1980, fl., $B$. Stergios 1712 (VEN). SUCRE: San Juan-Cancamure, 14.XII.1982, fl., L. Cumaná 1209 (VEN). VARGAS: along Río Los Caracas above town of Los Caracas, 11.II.1973, fl., T. Croat $21550(\mathrm{VEN})$.

Abarca todos los estados al norte y sur del Orinoco (Fig. 6), desde los 0 hasta $1.300 \mathrm{~m}$, y crece en zonas urbanas intervenidas, áreas verdes y jardines, así como en áreas rurales. Es la especie más colectada y con morfología variable del género Merremia en Venezuela. Se distingue por la apariencia umbeliforme de las inflorescencias y sus flores amarillas. A menudo se puede observar la variación en la cobertura de la pubescencia sobre las estructuras vegetativas, las cuales pueden ser completamente glabras hasta medianamente densas, pero permitiendo observar la epidermis abaxial de las hojas.
12. Merremia wurdackii D.F. Austin \& Staples, Mem. New York Bot. Gard. 32: 320. 1981. Fig. 7

Hierbas volubles; tallos teretes, 1,5-2 mm diám., lisos. Hojas simples, enteras; pecíolos teretes, 15-23×1 mm; láminas foliares ovadas, discoloras, base cordada, a veces auriculada, ángulo obtuso, margen entero, ápice agudo o atenuado, con mucrones, 7,3-8,5 × 3-3,5 cm, nerviación actinódroma. Tallos y pecíolos con tricomas tuberculados, translúcidos, a veces amarillentos o blancos, erectos, con cobertura densa, distribuidos en toda la extensión; láminas foliares con tricomas por la cara adaxial y abaxial, translúcidos, blancos, tuberculados, erectos. Inflorescencias en dicasios de hasta 3 flores o reducidas a 1 flor; pedúnculo terete, 1,7-20 × 0,9-2 mm; pedúnculos y pedicelos con tricomas, en toda la superficie, translúcidos, a veces blancos, tuberculados, erectos, con cobertura densa; brácteas caducas, ovadas o elípticas. Flores hasta 3,9 cm de largo; pedicelos teretes, hasta $5 \times$ $1,5 \mathrm{~mm}$; cáliz de 5 sépalos, distinguidos en dos series, libres entre sí, con prefloración imbricada, ovados, a veces elípticos, obtusos en la base, margen entero, rectos, ápice agudo; sépalo más externo, 12-26×11-14 mm, sépalo más interno hasta $21 \mathrm{~mm}$ de largo, con tricomas tuberculados, translúcidos o blancos, ascendentes o erectos, con cobertura medianamente densa; corola amarilla, glabra; bandas mediapetalinas discoloras; estigma 1, esférico. Fruto indehiscente, globoso, ca. $8 \mathrm{~mm}$ diám.; superficie del exocarpo rugosa; sépalos persistentes y acrescentes en el fruto, paralelos al eje, hasta $7 \mathrm{~mm}$ de largo, con 4 septos. Semillas 4 por fruto, $8-9 \mathrm{~mm}$ de largo, con tricomas simples.

Material seleccionado: AMAZONAS: Departamento Atures, Santa Rosa de Ucata, alrededor del poblado, 18.IV.1989, fr., G. Romero \& F. Guánchez 1809 (VEN). BOLÍVAR: frequent in wet savanna and ascending rocks, Isla Santa Elena, Río Orinoco opposite mouth of Río Pargueni, 13.XII.1955, fl., J.J. Wurdack \& J.V. Monachino 39865 (NY, imagen digital vista).

Poco colectada y sólo se ha reportado en la zona noroeste de los estados Amazonas y Bolívar, al sur del Orinoco (Fig. 7), generalmente en zonas intervenidas y sabanas. A diferencia de $M$. umbellata, las flores son de mayor tamaño y con dos grandes bractéolas en la base de la ramificación del dicasio floral, las cuales tienen marcas rojizas hacia los ápices, y por la superficie de apariencia rugosa, formada por los tricomas tuberculados muy cortos presentes en la cara abaxial de las hojas y otras estructuras vegetativas. 


\section{Consideraciones Finales}

Desde la publicación del primer tratamiento de la familia Convolvulaceae para Venezuela se han realizado pocos cambios en el género Merremia, siguiendo vigente la propuesta nomenclatural de Austin (1982). Con la presente revisión se amplían las descripciones del género Merremia para el país y el rango de distribución de cada uno de los taxones en el territorio nacional como resultado del mayor número de exsicatas considerado en el presente estudio. En este sentido, se confirma la presencia de M. aegyptia en el estado Bolívar, $M$. cissoides en Aragua, $M$. dissecta en los estados Falcón, Monagas y Vargas, M. macrocalyx en Cojedes, $M$. quinquefolia en Falcón, Sucre y Vargas, M. tuberosa en Táchira y Zulia, y M. umbellata en Amazonas, Falcón, Mérida y Vargas. Asimismo, se proponen nuevos caracteres diagnósticos como tipos y distribución de los tricomas obtenidos con la aplicación del programa computacional DELTA, y se cuenta con un análisis morfológico más completo de los principales caracteres discriminatorios, logrando una clave utilizando sólo caracteres vegetativos para discriminar las especies presentes en el país. Estos aportes permitieron una mejor resolución en la circunscripción taxonómica de las especies de Merremia, principalmente en el complejo M. cissoides-M. quinquefolia en Venezuela.

\section{Agradecimientos}

A la Fundación Instituto Botánico de Venezuela, por el financiamiento y apoyo en la logística; al Herbario Nacional de Venezuela (VEN) por poner a disposición su base de datos; a la prof. Carmen Emilia Benítez por sus observaciones sobre nomenclatura taxonómica y a los curadores de MY, PORT y GUYN por los préstamos de los pliegos. Este trabajo es producto de la asignatura Herramientas Computacionales para el Análisis Taxonómico, del Postgrado en Botánica (Instituto de Biología Experimental, UCV) y del Postgrado en Botánica y Taxonomía Neotropical (ULA).

\section{Referencias}

Austin, D.F. \& Staples, G.W. 1981. Convolvulaceae. In: Maguire, B. (ed.). The botany of the Guayana highlands, Part XI. Memoires of the New York Botanical Garden 32: 309-323.

Austin, D.F. \& Staples, G.W. 1983. Additions and changes in the neotropical Convolvulaceae: notes on Merremia, Operculina, and Turbina. Journal of the Arnold Arboretum 64: 483-489.
Austin, D.F. 1982. Convolvulaceae. In: Luces de Febres, Z. \& Steyermark, J.A. (eds.). Flora de Venezuela 8: $15-226$.

Bharathan, G. \& Sinha, N.R. 2001. The regulation of compound leaf development. Plant Physiology 127: 1533-1538.

Bell, A.D. 1991. An illustrated guide to flowering plant morphology. Oxford University Press, New York. 341p.

Champagne, C. \& Sinha, N.R. 2004. Compound leaves: equal to the sum of their parts? Development 131: 4401-4412.

Dallwitz, M.J. \& Paine, T.A. 1993 onwards. Definition of the DELTA format. Disponible en <http://deltaintkey.com>. Acceso en 15 Julio 2008

Demissew, S. 2001. A synopsis of the genus Merremia (Convolvulaceae) in the flora of Ethiopia and Eritrea. Kew Bulletin 56: 931-943.

Dennstedt, A.W. 1818. Schlüssel zum Hortus Indicus Malabaricus, oder dreifaches Register zu diesem Werke. Verlag des Landes-Industrie-Comptoirs, Weimar. 40p.

Dilcher, D.L. 1974. Approaches to the identification of angiosperm leaf remains. The Botanical Review 40: 1-157.

Endlicher, S. 1841. Genera plantarum secundum ordines naturales disposita. Vol. 1. F. Beck, Vindobonae. 1484p.

Ferguson, I.K.; Verdcourt, B. \& Poole, M.M. 1977. Pollen morphology in the genera Merremia and Operculina (Convolvulaceae) and its taxonomic significance. Kew Bulletin 31: 763-773.

Ferrer-Pereira, H.E.; Vivas-Arroyo, Y.; Nozawa, S.; Hokche, O.; Pérez-Cortéz, S.; Rodríguez, L.; Mostacero, J. \& Estrada, J. 2010. Aplicación de herramientas computacionales al estudio morfotaxonómico del género Merremia (Convolvulaceae) en Venezuela. Rodriguésia 61: 661-668.

Font Quer, P. 1953. Diccionario de botánica. Ediciones Península, Barcelona. 1244p.

Hallier, H. 1893. Versuch einer natiirlichen Gliederung der Convolvulaceen auf morphologischer und anatomischer Grundlage. Botanische Jahrbücher für Systematik 16: 453-591.

Hallier, H. 1913. Convolvulaceae. In: Winkler, H. (ed.). Beiträge zur Kenntnis der Flora von Borneo III, Botanische Jahrbücher für Systematik 49: 378-380.

Hickey, L. 1973. Classification of the architecture of dicotyledonous leaves. American Journal of Botany 60: 17-33.

Leite, K.R.B.; Simão-Bianchini, R. \& Santos, F.A.R. 2005. Morfologia polínica de espécies do gênero Merremia Dennst. (Convolvulaceae) ocorrentes no estado da Bahia, Brasil. Acta Botanica Brasilica 19: 313-321.

Nishida, S. 1999. Revision of Beilschmiedia (Lauraceae) in the Neotropics. Annals of the Missouri Botanical Garden 86: 657-701. 
O’Donell, C.A. 1941. Revisión de las especies americanas de Merremia (Convolvulaceae). Lilloa 6: 467-554.

Ooststroom, S.J. 1939. The Convolvulaceae of Malaysia, II. The genera Jacquemontia, Aniseia, Convolvulus, Calystegia, Shutereia, Merremia, Operculina and Decalobanthus. Blumea 3: 267-371.

Ooststroom, S.J. \& van Hoogland, R.D. 1953. Convolvulaceae. In: van Steenis, C.G.G.J. (ed.). Flora Malesiana 1: 388-512.

Payne, W.W. 1978. A glossary of plant hair terminology. Brittonia 30: 239-255.

Pittier, H.F.; Badillo, V.M.; Lasser, T.; Schnee, L. \& Luces, Z. 1945. Catálogo de la flora venezolana. Litografía y Tipografía Vargas, Caracas. 576p.

Rhui-cheng, F. \& Staples, G. 1995. Convolvulaceae. In: Wu, Z.G. \& Raven, P.H. (eds.). Flora of China 16: 291-299.
Simão-Bianchini R. \& Pirani, J.R. 1997. Flora da Serra do Cipó, Minas Gerais: Convolvulaceae. Boletim de Botânica da Universidade de São Paulo 16: 125-149.

Stefanovic, S.; Austin, D.F. \& Olmstead, R.G. 2003. Classification of Convolvulaceae: a phylogenetic approach. Systematic Botany 28: 791-806.

Stefanovic, S.; Krueger, L. \& Olmstead, R.G. 2002. Monophyly of the Convolvulaceae and circumscription of their major lineages based on DNA sequences of multiple chloroplast loci. American Journal of Botany 89: 1510-1522.

Tapias, R. 2008. Convolvulaceae. In: Hokche, O.; Berry, P.E. \& Huber, O. (eds.). Nuevo catálogo de la flora vascular de Venezuela, Caracas. Pp. 339-344.

Lista de Exsicatae

Agostini, G. 361 (2); 433 (5); 1054 (5); Alfonzo, A. 23 (11); Aristeguieta, L. 4 (11); 2168 (2); 4023 (3); 4085 (5); 4088 (11); 4105 (8); 4106 (4); 5194 (9); 5341 (9); 5969 (11); 6875 (5); Badillo, V. 391 (11); 698 (11); Barreto, M. 9 (11); Bernardi, A. 6920 (5); Bianco, F. 71 (11); Blanco, C. 16 (11); Blohm, H. 4 (2); Brewer, Ch. 47 (2); Bunting, G. 4310 (2); 4423 (8); 5939 (11); 5952 (1); 6323 (4); 6952 (11); 8298 (11); 8679 (5); 10053 (8); 11066 (5); Cardona, F. 153 (2); 268 (2); 360 (2); 682 (2); 3044 (2); 3059 (2); Castillo, A. 246 (1); 2620 (11); 2782 (11); 2788 (11); 3031 (1); Chacón, Y. 13 (9); Chaviel, A. 708 (2); 737 (5); Colella, M. 570 (5); 1235 (2); Cotton, E. 85 (5); Croat, T. 21344 (11); 21550 (11); 21585 (1); 21660 (11); 21719 (5); 74407 (5); 74425 (7); Cuello, N. 58 (5); Cumaná, L. 1090 (1); 1091 (4); 1156 (5); 1209 (11); Cáseres, A. 2 (5); Davidse, G. 3911 (11); 3954 (1); 5052 (5); 13082 (11); 13839 (11); 14784 (11); 16468 (11); 16574 (5); 19393 (5); 19471 (5); 23083 (2); De Martino, G. 1115 (11); Delascio, F. 2819 (11); 4157 (5); 8658 (11); 9746 (11); 12975 (11); 15137 (11); 18290 (2); 19283 (1); Delgado, L. 22 (11); 2245 (5); di Genova, T. s/n (11); Díaz, W. 18 (5); 8247 (5); 8671 (2); Edwards, K. 345 (5); Ehrendorfer, F. 74107-2 (2); Fernández, A. 2557 (2); 2973 (2); Ferrari, G. 1337 (11); 1568 (10); 1581 (5); Ferrer-Pereira, H. 293 (8); 295, 296 (9); 302 (11); 317, 318 (4); 320 (1); 451 (5); 756,757 (8); 768 (4); 770 (8); Frontado, M. MF-014 (8); Fuenmayor, N. 4 (1); García, T. 32 (5); Gentry, A. 10415 (9); 10733 (11); 11118 (11); 14431 (6); 14476 (6); 24825 (5); González, A. 3 (1); 5 (7); González, F. 4 (4); González, N. 10 (1); González, R. 30 (11); González, T. s/n (11); Gröger, A. 443 (6); 1145 (6); Guánchez, F. 641 (2); 3722 (3); 4192 (11); Hernández, L. 370 (5); Hokche, O. 2 (11); Holst, B. 2023 (5); Holt, E. 159 (11); 170 (10); 207 (10); Hoyos, J. 4199 (4); 4555 (4); 4557 (1); 4850 (4); Huber, O. 694 (2); 902 (2); 2117 (2); 2308 (2); 2317 (2); 2364 (2); 3550 (2); 3560 (2); 4452 (2); 6002 (5); 10504 (2); 7572 (2); 7805 (2); 8326 (2); 8356 (5); 11279 (2); 11622 (2); Ijjász, E. 113 (8); 566 (11); 567 (5); Jeffrey, C. 2411 (5); Killip, E. 37201 (5); 37242 (2); Knab-Vispo, C. 1181 (5); 1196 (11); 1384 (3); Koyama, T. 7207 (9); Larez, A. 212 (5); 736 (5); 750 (11); 1469 (2); 2522 (11); 3298 (1); Lasser, T. 3298 (1); Licata, A. 722 (5); Liesner, R. 5480 (2); 9266 (5); 10708 (5); 11326 (2); 19465 (5); Lourido, J. 8 (5); López, M. 60 (1); López, R. 482 (5); López-Palacios, S. 1786 (11); 1928 (9); Manara, B. s/n VEN- 171384 (11); s/n VEN- 171393 (1); s/n VEN- 172639 (5); s/n VEN175055 (11); s/n VEN- 218034 (10); s/n VEN- 249984 (4); s/n VEN- 309987 (2); Marín, E. 1632 (5); Mateu, V. 13 (1); Meier, W. 798 (1); 2239 (5); 8914 (11); 11266 (11); 11267 (8); 11277 (1); Mocquerys s/n VEN- 191249 (8); s/n VEN- 192014 (1); Montes, R. 315 (5); Morillo, G. 510 (5); 930 (5); 2853 (11); 2856 (1); 2957 (11); 2959 (8); 3035 (5); 3242 (10); 3704 (5); 3826 (1); 6654 (6); N. G. S. 152 (3); 90 (9); Niermillier, A. 157 (11); Nozawa, S. 240 (6); Nucette, E. 167 (11); Parra, N. 13 (1); Pittier, H. 7600 (5); 7790 (5); 8267 (1); 8671 (1); 9886 (5); 11643 (1); 11660 (10); 12088 (5); 12607 (8); 14646 (5); 14680 (11); 14728 (9); 15318 (5); Pulido, R. 6 (5); Pursell, R. 8087 (1); 8125 (5); 8152 (11); 8201 (11); 8722 (9); Pérez, L. 7 (5); Ramia, M. 652 (5); 4117 (11); 4131 (11); 4895 (11); 4947 (11); 4958 (1); 5092 (11); 5481 (11); Ramírez, I. 306 (5); Ramírez, N. 59 (5); 361 (7); Reyes, M. 9 (11); Riina, R. 261 (1); Roberston, K. 113 (4); 135 (11); 144 (11); 182 (9); Romero, G. 1701 (6); 1809 (12): Rosales, G. 15 (1); 19 (5); Rutkis, E. 370 (11); 736 (5); Saer, J. 248 (7); 294 (7); 347 (11); 665 (7); Salazar, Y. 3 (9); 16 (1); 49 (11); 140 (9); Santibañez, A. 11 (11); 13 (1); Silva, A. 1014 (5); Smith, R. V69 (7); V763 (11); V6074 (1); V7966 (4); V7993 (5); Solorzano, R. 11 (11); Stergios, B. 1712 (11); 8844 (9); 10885 (2); 11104 (2); Steyermark, J. 61183 (5); 88296 (5); 88921 (3); 89868 (5); 90687 (5); 97027 (4); 102329 (11); 102417 (10); 103432 (7); 103644 (7); 106349 (2); 107087 (5); 108677 (11); 110064 (7); 111334 (5); 111505 (5); 111881 (5); 112279 (5); 116432 (5); 121251 (1); 121399 (8); 124299 (9); 124728 (5); 124982 (10); 127199 (1); 131595 (6); 131636 (2); Tamayo, F. 1009 (1); 2735 (2); 3250 (5); Tapias, B. 20 (1); Togo, l. 1 (4); Valera, A. 593 (2); Vilealdo 13 (11); Vivas, J. 60 (7); Vivas, Y. 1722 (9); Williams, Ll. 11240 (11); 11484 (5); 11588 (5); 11736 (2); 11858 (2); 11958 (2); 12506 (2); 12527 (11); 12670 (3); 12862 (9); 12980 (6); 13391 (2); 13439 (2); 13453 (6); 16025 (6); 16052 (2); Wood, Ch. 373 (11); 492 (10); 495 (10); Xena, N. 256 (5); Yánez, M. 224 (5); Zambrano, O. 1500 (11); Zent, S. 0287-17 (5). 